\title{
Regeneración natural y diversidad de especies arbóreas en selvas húmedas
}

\author{
Miguel MARTÍNEZ RAMOS ${ }^{1}$
}

\begin{abstract}
RESUMEN. Uno de los grandes enigmas de la biología tropical es el de cómo en las selvas altas perennifolias se mantiene una enorme cantidad de especies de árboles a escalas locales tan pequeñas como una hectárea. Esta revisión explora la relación entre la dinámica de regeneración natural de estos bosques y los procesos y mecanismos (evolutivos y ecológicos) que facilitan el mantenimiento de tan extraordinaria diversidad. Como primer punto, se hace una breve revisión de las ideas sobre el origen de la diversidad de especies arbóreas en los trópicos. Se sugiere que a nivel local: i) fenómenos históricos (de índole evolutivo y biogegráfico) son determinantes de la riqueza de especies, y ii) que las comunidades de árboles de selvas altas perennifolias parecen no estar saturadas de especies, de modo que, una especie recién originada puede migrar libremente a través de una región. Como segundo punto, se dan detalles sobre cómo ocurre el proceso de la regeneración natural. La dinámica de formación de claros, promovida por la caída de ramas y árboles, es un componente fundamental en la renovación del dosel. Los claros pequeños facilitan el desarrollo de plántulas y árboles jóvenes mientras que los claros grandes permiten a los árboles alcanzar tallas reproductivas. La apertura de claros y el ingreso de nuevos árboles en el dosel son los extremos de un proceso dinámico de reemplazamiento de árboles y especies en el dosel de la selva. Como tercer y último punto, se relaciona el proceso de reemplazamiento de árboles con el mantenimiento de la diversidad de especies arbóreas a una escala local. Se argumenta que aquellos factores que promueven una elevada diversidad de especies en la comunidad de plántulas y árboles jóvenes que crece bajo los árboles maduros favorecen una frecuencia alta de reemplazos entre árboles heterospecíficos y por lo tanto, facilitan el mantenimiento de la diversidad de especies en el dosel. Entre estos factores, los animales frugívoros, que promueven diversidad en la lluvia de semillas, y los agentes bióticos de mortalidad de semillas,
\end{abstract}

' Centro de Ecología, Universidad Nacional Autónoma de México. Apdo. Postal 70-275. Delegación Coyoacán. 04510, México, D.F.

Martínez-Ramos M. 1994. Regeneración natural y diversidad de especies arbóreas en selvas húmedas. Boletín de la Sociedad Botánica de México 54: 179-224. 
plántulas y árboles jóvenes que actuan principalmente sobre especies abundantes son facilitadores clave de la diversidad. La existencia de disyuntivas en los atributos de historia de vida (amplitud en la dispersión de semillas, sobrevivencia en sombra y crecimiento en los claros) de los árboles coadyuva al mantenimiento de la diversidad favoreciendo el reemplazamiento de árboles con diferentes historias de vida.

La presente revisión no apoya la idea de que el mantenimiento de la diversidad de especies arbóreas en las selvas húmedas depende de procesos estocásticos, como algunos autores han propuesto. Por el contrario, se concluye que los fenómenos ecológicos tienen un papel preponderante en definir la posibilidad que tiene una especie de ganar una posición en estos bosques altamente diversos.

ABSTRACT. One of the major biological mysteries still to be explained is the maintenance of the enormous local tree species diversity in tropical rain forests. This review explores the relationship between the dynamics of natural regeneration and the evolutionary and ecological processes and mechanisms involved in the origin and maintenance of such extraordinary diversity. First, I review ideas on the origin of tree species diversity in the tropics. This review suggests that: i) historical, evolutionary and biogeographical phenomena have a paramount influence on local species richness, and ii) tropical rain forest tree communities are species unsaturated, suggesting that newly originated species may freely migrate across a regional landscape. Second, I describe the forest regeneration process. Gap dy namics, promoted by branch and tree falls, is a fundamental component of the forest canopy renewal. Small gaps (caused by branch falls) facilitate the establishment and survival of seedlings and saplings in the shaded understory (advanced regeneration), whereas large gaps (caused by tree falls) enable trees to reach mature sizes. Gap creation and tree maturation are the extremes of a process of tree and species repiacement in the forest canopy. Third, I explore relationships between the tree replacement process and the population and community mechanisms that facilitate maintenance of species diversity at a local scale of a few hectares. I argue and document that factors that promote high species diversity in the advanced regeneration favor high probabilities of heterospecific replacements among canopy trees. Hence, these factors facilitate the maintenance of species diversity in the forest canopy. Frugivores, by promoting diversity in the seed rain community, and biotic agents of seed, seedling and sapling mortslity by operating mainly on abundant species, are key factors in facilitating diversity. Furthermore, the existence of tradeoffs in tree life history attributes (such as seed dispersal capacity, survivorship in the shade and growth under gap conditions) contributes to diversity maintenance by promoting heterospecific replacements.

This review does not support the idea that maintenance of tree species diversity in tropical rain forest depends on random processes, as some authors have claimed. Instead, I conclude that ecological phenomena have a paramount role on the possibility that a species gains a membresy in such highly diverse forests. 
Los bosques tropicales húmedos (tropical rain forest sensu Richards, 1957), selvas altas perennifolias (sensu Miranda y Hernández-X, 1963), bosques tropicales perennifolios (sensu Rzedowski, 1978), o simplemente selvas húmedas, son sistemas biológicos notablemente diversos y dinámicos. Para ejemplificar su diversidad, basta mencionar que en estas selvas es común encontrar, en una superficie de tan sólo una hectárea, un poco más de 100 árboles con un diámetro del tronco a la altura del pecho (dap) mayor a $10 \mathrm{~cm}$ que representan entre 50 y 300 especies (Whitmore, 1984; Bongers et al., 1988; Gentry, 1990). La dinámica de estos bosques puede ejemplificarse con el hecho de que estas comunidades arbóreas se renuevan en lapsos que varían entre 50 a 400 años (Lieberman et al., 1985a; Clark, 1990; Hubbell y Foster, 1986a, 1990a). En el presente trabajo, quisiera abordar algunos aspectos ecológicos que son centrales para entender los fenómenos que mantienen la diversidad de especies arbóreas en las selvas húmedas a la escala local de una o pocas hectáreas. En particular, argumentaré que aquellos aspectos ecológicos relacionados con la llamada "dinámica de regeneración natural" juegan un papel sobresaliente al respecto.

Sin duda, esta presentación será parcial. No obstante que los aspectos que se abordarán tienen una perspectiva básica, la información que se provee también es útil para los estudios cuyo interés esté centrado en problemas relacionados con la conservación y el manejo de recursos forestales tropicales. Gran parte de la información utilizada en este trabajo proviene de estudios realizados en la Estación de Biología Tropical "Los Tuxtlas", Veracruz, México (ver detalles sobre la localidad en Gómez-Pompa y Del Amo, 1985) y de otras selvas, principalmente de regiones neotropicales.

\section{REGENERAACIÓN NATURAL Y LA DIVERSIDAD DE ESPECIES ARBÓREAS}

Para los sistemas boscosos, el término regeneración puede asignarse a un proceso natural de recambio de árboles. Este proceso, en un sentido general, podría definirse como el reemplazamiento de un conjunto de árboles, que han llegado a su etapa madura, por otros considerando una unidad de espacio y tiempo definidos. El proceso tiene dos componentes: el primero se refiere a la caída natural de los árboles maduros (los cuales constituyen el dosel del bosque), y el segundo, se refiere al reclutamiento de árboles que reemplazan a aquellos que van dejando lugares vacantes. Los árboles reclutas provienen de una o varias de las siguientes fuentes de propágulos (ver más adelante la fig. 2): i) semillas latentes en el suelo, ii) semillas recién dispersadas, iii) plántulas y árboles jóvenes que se establecen antes de que ocurra la caída de un árbol, y iv) rebrotes de árboles rotos. Las especies pueden tener una o varias de tales fuentes de propágulos, las cuales, como se detallará más adelante, tienen 
su desarrollo más importante cuando éstos son estimulados por las condiciones ambientales que aparecen tras la caída de árboles (Bazzaz, 1984; Gorchov et al., 1993).

¿Qué relación guarda la regeneración natural con el mantenimiento de la diversidad de especies arbóreas? En general, la respuesta se relaciona con la manera en la que ocurre el reemplazamiento entre árboles que pertenecen a diferentes especies. Por ejemplo, imaginémonos dos escenarios hipotéticos extremos. En uno, una especie posee medios regenerativos qụe la hacen capaz de ocupar los huecos del dosel con una probabilidad mucho mayor a las del resto de las especies. A la larga, este proceso conduciría a reemplazos entre árboles coespecíficos y a una comunidad arbórea prácticamente monoespecifica. En el otro extremo, todas las especies poseen la misma probabilidad de reemplazar a otras. Suponiendo una distribución espacial aleatoria de los propágulos, a largo plazo este proceso conduciría a reemplazos heteroespecíficos y a una comunidad arbórea diversa en especies. Por supuesto, entre estos extremos pueden ocurrir una gama amplia de situaciones intermedias. Desde el punto de vista biológico, es interesante averiguar los atributos por los cuales los árboles de distintas especies se apropian del espacio dejado por la caída de otros. La cuestión medular que es importante averiguar es si estos atributos determinan que las probabilidades de reemplazo entre especies se apartan de aquellas esperadas meramente por el azar (Hubbell y Foster, 1986b).

Para explorar la relación que guarda el reemplazamiento de árboles con el mantenimiento de la diversidad, quisiera abordar en primer lugar aspectos que definen el número de especies que existen en una localidad y que potencialmente pueden intervenir en el proceso de reemplazamiento. Como veremos, este número es resultado de fenómenos que ocurren a través de escalas evolutivas y biogeográficas. Después de revisar brevemente este aspecto, daré detalles acerca de cómo ocurre la regeneración natural de las selvas altas perennifolias. Finalmente, relacionaré el proceso de reemplazo entre árboles y el mantenimiento de la diversidad de especies arbóreas, destacando algunos mecanismos que pueden estar operando en esta relación.

\section{ORIGEN DE LA DIVERSIDAD DE ESPECIES EN LAS SELVAS HÚMEDAS}

Típicamente, una selva húmeda posee elementos arbóreos perennifolios y un dosel que alcanza 30 ó más metros de altura. Estos bosques ocurren en tierras de altitud baja (<500 m.s.n.m) y en climas cálido-húmedos, donde la cantidad total de lluvia en un año es mayor de $2,000 \mathrm{~mm}$ y la temperatura promedio durante el año es de $23{ }^{\circ} \mathrm{C}$ o más (Rzedowski, 1978). Por unidad de área, estos bosques poseen muchas más especies que sus contrapartes templadas (Gentry, 1988, 1990); a la escala de una hectárea, algunas de especies son abundantes en árboles maduros pero la mayoría posee pocos (Hubbell y Foster, 1986c). Como ejemplo, considérese el caso de la selva 
presente en la Estación de Biología Los Tuxtlas. En una muestra de cinco hectáreas de selva, se encontraron 101 especies de árboles (dap $\pm 20 \mathrm{~cm}$ ) la mayoría de las cuales (>50\%) estaban representadas por menos de un árbol por hectárea (M. Martínez-Ramos, datos no publicados). En un censo de árboles (dap $\geq 20 \mathrm{~cm}$ ) llevado a cabo en un área de 50 ha en el bosque de la Isla de Barro Colorado, Panamá, se encontraron 186 especies $70 \%$ de las cuales exhibieron densidades menores a un árbol por hectárea (Hubbell y Foster, 1983).

Tomando en consideración tan extraordinaria diversidad de especies existen dos preguntas que pueden considerarse como enigmas biológicos: i) ¿qué origina tal diversidad? y ii) ¿qué fenómenos permiten su mantenimiento? (Hubbell y Foster, 1986b; Leigh, 1990). Estas preguntas son también de amplio interés en biología. La primera pregunta se relaciona con fenómenos históricos (evolutivos y biogeográficos) y la segunda con fenómenos ecológicos que afectan la dinámica de las poblaciones y la organización de las comunidades (ver por ejemplo, Ricklefs y Schulter, 1993).

El número de especies de plantas y animales aumenta, como tendencia general, desde los polos hacia las regiones ecuatoriales (Primack, 1993). En esta tendencia, el valor máximo de diversidad de especies arbóreas ocurre en las selvas húmedas (Gentry, 1988). Por lo tanto, es de esperarse que el entendimiento del origen de la diversidad de especies arbóreas en las selvas tiene que ver con las causas que dan lugar al patrón planetario de cambio en la diversidad de especies.

Se ha propuesto que tales causas descansan en fenómenos históricos, de eventos de especiación y migración de especies que han ocurrido a través de grandes extensiones geográficas y largos periodos de tiempo (Ricklefs y Schulter, 1993). De un modo general, el número de especies presente en una región dada en un momento dado, depende del balance entre las tasas de especiación, extinción, inmigración y emigración de especies (MacArthur y Wilson, 1967). Por ejemplo, si las tasas de extinción y emigración superan a aquellas de especiación e inmigración el número neto de especies tendería a reducirse. Por el contrario, una mayor tasa de especiación respecto a la de extinción, o una de inmigración mayor a la de emigración, tendería a aumentar el acervo regional de especies.

Se piensa que el ambiente que impera en las regiones cálido-húmedas tropicales ha favorecido elevadas tasas de especiación y tasas bajas de extinción de especies (Dobzhansky, 1950). Para regiones extratropicales, se presume que eventos catastróficos recurrentes y/o condiciones limitantes severas aumentan las tasas de extinción de especies sobre aquellas de especiación (Leigh, 1990). Este balance daría lugar a números de especies más bajos en las zonas extratropicales que en las regiones tropicales cálido-húmedas.

Algunas hipótesis señalan como fuente importante de diversidad a mecanismos de especiación simpátrica. Por ejemplo, Federov (1966) propuso que la especiación 
por deriva génica puede ser frecuente en las selvas húmedas dado que muchas poblaciones poseen un número muy reducido de árboles que pueden intercambiar material genético. Otros han propuesto que las diversas e intensas interacciones entre los árboles y sus posibles competidores, depredadores y mutualistas han actuado como fuertes agentes selectivos que han conducido a la segregación de caracteres y a un activo proceso de especiación (ver revisión en Asthon, 1969; Leigh, 1990). Se piensa que la acumulación de especies originadas por inedio de este mecanismo puede facilitarse si en el ambiente tropical existen amplios y abundantes gradientes de recursos y una baja frecuencia de eventos de mortalidad catastróficos. Esto implicaría que las especies nuevas poseen atributos que les permiten explotar recursos no usados por las especies ancestrales.

Opuesto a este punto de vista es aquel sostenido por Hubbell y Foster (1986b). En la selva de la Isla de Barro Colorado, Panamá, estos autores registraron, en promedio, a 15 especies entre los 20 árboles más cercano a un árbol focal elegido al azar y que dos árboles focales de la misma especie compartieron, en promedio, sólo un $30 \%$ de especies vecinas (Hubbell y Foster, 1983, 1986b). Interpretados de otro manera, estos resultados sugieren que el vecindario de especies con el que interactúa una población de árboles es cambiante e impredecible, dentro de una misma generación y entre distintas generaciones. Basados en estas observaciones, Hubbell y Foster sostienen que la evolución por segregación de caracteres sería una fenómeno poco probable ya que para que tal fenómeno ocurra es necesario que parejas de especies interactúen de manera directa y consistente a través de múltiples generaciones (tal como lo señala el "axioma de Gaus"; Gaus, 1934). Por el contrario, si el vecindario de competidores es impredecible debería esperarse la evolución de caracteres convergentes que darían a una especie la oportunidad de competir con cualquiera otra. Este fenómeno de coevolución difusa conduciria a la aparición de especies ecológicamente equivalentes, que ocuparian amplias zonas adaptativas. Funcionalmente, las especies representarían gremios ecológicos ricos en especies, de lo cuál existe cierta evidencia (Martínez-Ramos, 1985; Hubbell y Foster, 1986c, 1987).

Un escenario evolutivo como el anterior puede relacionarse con las hipótesis que sugieren que el origen de la diversidad de especies encontrada a una escala local tiene que ver con fenómenos de deriva génica $y$, en especial, con fenómenos de especiación alopátrica y migración de especies (Prance, 1982). Se ha estimado que el origen de la flora actual de las selvas húmedas tuvo su origen hace 100 a 110 millones de años, en la parte occidental (área ecuatorial actual de Africa) del macrocontinente llamado Gondwana (Cronquist, 1981; Raven y Axelrod, 1974). Estas angiospermas ancestrales se extendieron rápidamente hacia el otro macrocontinente desprendido de Pangea: Lauracia. De esta flora inicial surgieron linajes que actualmente conforman muchos taxa de arboles encontrados actualmente en las selvas húmedas. 
Se ha establecido que muchas de las especies encontradas en las selvas húmedas de México tiene linajes originados en ambos macrocontinentes. Wendt (1993) recientemente propuso que la flora de árboles (que alcanzan al menos $18 \mathrm{~m}$ de altura) encontrada en la mayoría de las selvas altas perennifolias y medianas subperennifolias del país tiene tres orígenes principales: i) un grupo de elementos antiguos cuyos linajes se originaron en Lauracia, ii) un grupo de elementos cuyos linajes se originaron en Gondwana pero que arribaron a Norteamérica vía la conexión entre Lauracia (en lo que hoy es Europa) y Gondwana (en lo que hoy es Africa) y iii) un grupo de elementos cuyos linajes provenieron de América del Sur (en Amazonia). Este último grupo representan la fuente de inmigración más reciente de taxa tropical a México.

Tal linaje ancestral puede explicar el por qué la mayoría de las selvas neotropicales se encuentran dominadas taxonómicamente por pocas familias (cuadro 1). La historia de cambios dinámicos en la tectónica de placas, clima, topografía, orogenia y evolución de suelos ha propiciado un proceso de especiación importante en México y otras regiones tropicales (Sarukhán, 1968; Gentry, 1982; Prance, 1982; Toledo, 1982; Salo, 1993; Gentry y Ortiz, 1993). Así de la flora analizada por Wendt (1993), 9.6\% es endémica a México, $30.9 \%$ se restringe a México y norte de Centroamérica, $55 \%$ se comparte con toda Centroamérica y sólo el 25.1\% se encuentra también en Amazonia.

CUADRO 1. Principales familias inventariadas en parcelas de 1 ha en diferentes selvas húmedas neotropicales. Modificado de Gentry (1990); los datos para Los Tuxtlas provienen de Bongers et al. (1988). Por debajo de los nombres de la localidades se encuentra en paréntesis la ubicación latitudinal. Seguido al nombre de cada familia se muestra el número de especies encontradas en cada parcela considerando sólo árboles con dap $\geq 10 \mathrm{~cm}$.

\begin{tabular}{|c|c|c|c|c|c|}
\hline $\begin{array}{l}\text { Los Tuxtlas } \\
\text { México } \\
\left(18^{\circ} \mathrm{N}\right)\end{array}$ & $\begin{array}{c}\text { Fica La Selva } \\
\text { Costa Rica } \\
\left(10^{\circ} 15^{\prime} \mathrm{N}\right)\end{array}$ & $\begin{array}{l}\text { Barro Colorado } \\
\text { Panamá } \\
\left(9^{\circ} 9^{\prime} \mathrm{N}\right)\end{array}$ & $\begin{array}{l}\text { Manaos } \\
\text { Brasil } \\
\left(2^{\circ} 20^{\prime} \mathrm{S}\right)\end{array}$ & $\begin{array}{l}\text { Yanamono } \\
\text { Perú } \\
\left(3^{\circ} 55^{\prime} \mathrm{S}\right)\end{array}$ & $\begin{array}{c}\text { Cosha Cashu } \\
\text { Perú } \\
\left(11^{\circ} 54^{\prime} \mathrm{S}\right)\end{array}$ \\
\hline Leguminosae (24) & Leguminosae (30) & Leguminosae (12) & Leguminosae (19) & Leguminosae (43) & Leguminosae (27) \\
\hline Moraceae (11) & Moraceae (13) & Moraceae (7) & Lecythidaceae (18) & Moraceae (24) & Moraceae (18) \\
\hline Rubiaceae (10) & Lauraceae (13) & Flacurtiaceae (6) & Moraceae (13) & Myristicaceae (18) & Annonaceae (18) \\
\hline Lauraceae (8) & Euphorbiaceae (10) & Lauraceae (5) & Sapotaceae (11) & Euphorbiaceae (18) & Lauraceae (16) \\
\hline Sapotaceae (6) & Annonaceae (8) & Burceraceae (5) & Burseraceae (10) & Sapotaceae (16) & Sapotaceae (11) \\
\hline Annonaceae (4) & Sapotaceae (7) & Meliaceae (4) & Chrysobalanaceae (10) & Lauraceae (15) & Meliaceae (11) \\
\hline Euphorbiaceae (3) & Rubiaceaea (8) & Rubiaceae (4) & Vochysiaceae (8) & Rubiaceae (14) & Myristicaceae (7) \\
\hline
\end{tabular}


La hipótesis llamada de la "comunidad en deriva" (community drift) propuesta por Hubbell y Foster (1986b) puede asociarse con la idea de que los eventos biogeográficos y de evolución alopátrica son los principales determinantes de la riqueza regional de especies mientras que las tasas migración de especies determinan, en gran medida, la diversidad a una escala local. Esta hipótesis propone que si las especies son simétricas en su habilidad para competir por recursos comunes (de manera que no se excluyen) la probabilidad de que una especie llegue a extinguirse depende meramente del azar (es decir de su abundancia relativa en la comunidad). Por ejemplo, un modelo análitico de la hipótesis (que supone que no existe migración y que en la comunidad muere al año uno de cada cien árboles) predice que una especie, cuya abundancia fuese igual al 1\% de una comunidad de 2,000 árboles tardaría en desaparecer alrededor de 10,000 reemplazos entre arboles mientras que una con una abundancia igual al 10\% tardaria más de un millón de reemplazos (Hubbell y Foster, 1986b). Si se considera que, en promedio, cada reemplazo puede tomar 100 años (Martínez-Ramos, 1985), tales tiempos de extinción podrian ser suficientemente largos para que eventos de especiación compensen tal pérdida de especies.

El número neto de especies aumenta con el tiempo si las tasas de especiación superan a aquellas de extinción. No obstante, a una escala local se debería esperar que exista un limite a tal aumento debido a que los recursos (por ejemplo, el espacio) se agotan. Cuando se ha llegado a una reducción severa de los recursos, la riqueza local de especies debería depender más de la interacción competitiva (o de fenómenos ecológicos en general) entre especies que de los eventos de especiación y migración. Cornell y Lawton (1992) propusieron un modelo gráfico que evalua precisamente este punto. La gráfica tiene en el eje de las ordenadas a la riqueza local de especies y en el eje de las abscisas a la cantidad de especies que ocurre a una escala regional.

Si no hubiese saturación y las especies pudiesen migrar libremente de una localidad a otra se esperaria que la cantidad local de especies fuese una muestra aleatoria del acervo regional de especies; tal situaciön es representada en la gráfica por una recta. El modelo lineal sugiere que la riqueza local de especies depende más de fenómenos históricos que de los ecológicos. Lo contrario se implicaría si la riqueza local de especies alcanzase un limite a pesar de que el acervo regional de especies aumentase (una curva hiperbólica en la gráfica). Por supuesto, las comunidades "no saturadas" y "saturadas" son concepciones ideales. En realidad, las comunidades naturales pueden presentar caracteristicas que caen entre alguno de estos dos extremos.

Tomando como base el modelo propuesto por Comell y Lawton (1992), exploré la influencia de fenómenos históricos y ecológicos sobre la riqueza local de especies arbóreas de selvas húmedas neotropicales. Como acervo regional de especies consideré a los conjuntos floristicos de árboles (que pueden llegan a tener 10 cm 0 más de dap) que han sido registrados en las ảreas protegidas por Estaciones Biológicas. 
Tales áreas varían en extensión entre 700 a 1,500 ha. Consideré a la comunidad local de árboles (dap $\geq 10 \mathrm{~cm}$ dap) como el conjunto de especies censadas en parcelas de lha dentro de estas Estaciones. En total, pude rescatar información para siete de tales Estaciones, las cuales cubren un ámbito geográfico que varía desde Los Tuxtlas, México ( $19^{\circ}$ latitud norte), hasta el Manaos, Brasil ( ${ }^{\circ}$ latitud sur).

En la figura 1 puede apreciarse que existe una relación lineal entre la riqueza de especies por hectárea y la riqueza regional de especies. Esta tendencia sugiere que los fenómenos históricos son determinates importantes de la riqueza local de especies arbóreas en las selva húmedas analizadas. La tendencia también sugiere que tales comunidades arbóreas se encuentran bajo un estado de no saturación, es decir, que las interacciones competitivas (si es que existen) entre las especies no impiden la migración libre de especies a través de una región.

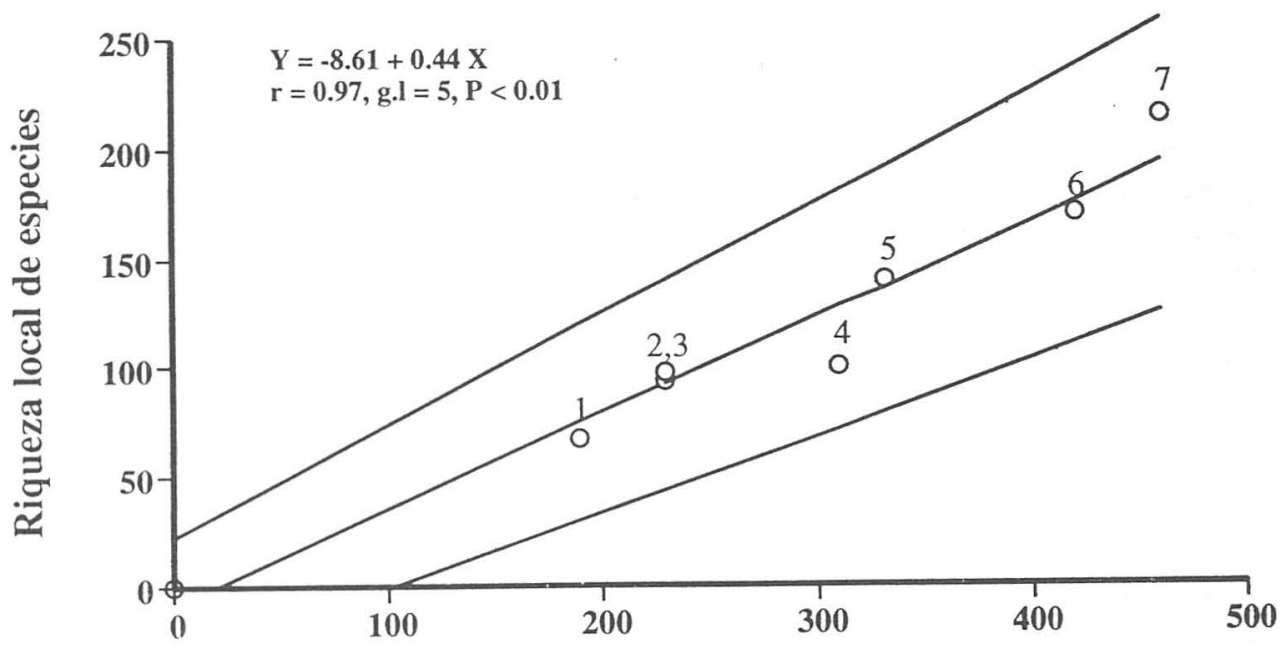

Riqueza de especies regional

Fig. 1. Relación entre el número de especies de árboles (dap $\geq 10 \mathrm{~cm}$ ) inventariadas en parcelas de 1 ha (Riqueza local de especies) y el número de especies registradas a la escala de 1,000 a 1,500 ha (Riqueza regional de especies) en diferentes selvas húmedas neotropicales: Los Tuxtlas, México (1), Chajul, México (2), Isla de Barro Colorado, Panamá (3), Finca La Selva, Costa Rica (4), Manú, Perú (5), Manaos, Brasil (6) y Chocó, Colombia (7). Se muestra el ajuste lineal con sus intervalos de confianza $(\mathrm{P}<0.05)$. Los datos se obtuvieron de Gentry (1990), para los sitios fuera de México, de Bongers et al . (1988), Ibarra (1985)e Ibarray Sinaca (1987) para Los Tuxtlas,y deE. Martínez y C. Ramos (comunicación personal) y M. Martínez-Ramos (datos no publicados) para Chajul. 
Como discuten Cornell y Lawton (1992), la dinámica de las poblaciones en comunidades no saturadas depende de factores azarosos que nulifican la exclusión competitiva entre especies. ¿Es esto aplicable al caso de las selvas húmedas? Posiblemente, pero es necesario documentar la ausencia de mecanismos regulatorios de las poblaciones y comunidades antes de aceptar que el azar y la historia son predominantes sobre los fenómenos ecológicos. Como se verá en la parte final de este ensayo, los organismos depredadores (que no actuan al azar sobre las especies de árboles) pueden también facilitar la coexistencia de muchas especies a nivel local. Además, la existencia de géneros con una gran cantidad de especies simpátricas (varias ecológicamente diferenciadas), como aquellas de géneros como Piper, Ficus y Psychotria, sugiere que la especiación a través de factores ecológicos contribuye a la generación de diversidad en los trópicos.

\section{EL PROCESO DE LA REGENERACIÓN NATURAL DE SELVAS HÚMEDAS}

Una selva húmeda puede idealizarse como un mosaico compuesto por fases regenerativas (ver revisiones en Whitmore, 1978, 1982; Brokaw, 1985a; Martínez-Ramos; 1985; Denslow, 1987). Estas fases se suceden entre sí de manera cíclica. El ciclo comienza con la caída de ramas grandes y árboles completos que al caer dejan huecos (o claros) en el dosel del bosque. En los huecos se producen fuertes cambios ambientales al interior del bosque como producto de su efecto sobre la vegetación (Fetcher et al., 1985). Los cambios ambientales estimulan un crecimiento vigoroso de las plantas que, con el tiempo, conduce a la clausura del claro (Whitmore, 1984). Visto de otra manera, este ciclo se completa cuando un árbol del dosel es reemplazado por otro.

En el proceso de la regeneración natural intervienen varios componentes de la comunidad que se encuentran interrelacionados. La figura 2 ilustra un esquema conceptual sencillo que trata de identificar los componentes más importantes del proceso de la regeneración natural del bosque. Cada componente es un subconjunto de la comunidad, conformado por individuos que comparten el mismo estadio de vida. Las flechas definen las transiciones que pueden darse entre los componentes. Comenzando con el componente que identifica a la comunidad de árboles maduros, existen dos transiciones posibles. Por un lado, los árboles maduros dan lugar a una lluvia de semillas, parte de la cuál se integra a un banco de semillas en los sitios cerrados de la selva (fig.2, ruta: $1 \rightarrow 3 \rightarrow$ ) y otra parte cae directamente en los claros (fig. 2 , ruta: $1 \rightarrow 11 \rightarrow$ ). Por otro lado, se desprenden ramas grandes o caen individuos completos de la comunidad de árboles maduros. Estas caídas dan lugar a los claros del bosque (fig. 2 , ruta: $2 \rightarrow 4 \rightarrow$ ). 


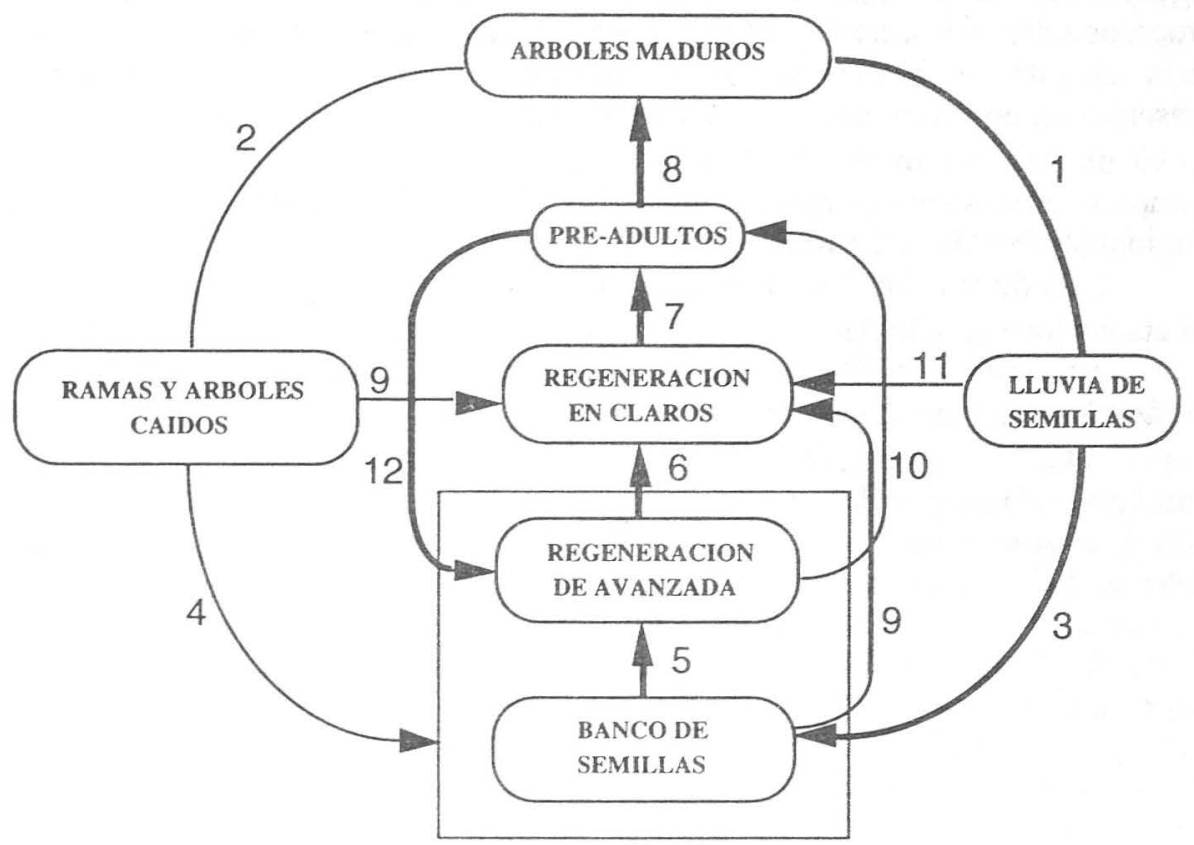

Fig. 2. Modelo conceptual del proceso de la regeneración natural de un bosque. Las celdas identifican a los componentes de la comunidad integrados por plantas que se encuentran en distintos estadios de vida. La regeneración avanzada comprende a plántulas y árboles jóvenes (generalmente menores de $5 \mathrm{~cm}$ de dap) encontrados en sitios del bosque con el dosel cerrado. El recuadro en gris define la regeneración encontrada bajo condiciones de sombra. La regeneración en claros se compone de semillas, plántulas, árboles jóvenes y retoños de árboles rotos que se encuentran en sitios recientemente abiertos por la caida de ramas grandes o árboles completos. Las flechas identifican las rutas que pueden seguir los miembros de cada componente a medida que se desarrollan de un estadio de vida a otro. Las flechas más gruesas identifican las transiciones más probables en las selvas húmedas. Los números facilitan la distinción de diferentes rutas hacia el estadio maduro de los árboles (ver texto para más detalles). 
En los sitios cerrados de la selva, la mayoría de las semillas transitan rápidamente al estadio de plántula y se integran a la comunidad denominada regeneración de avanzada, compuesta por plántulas y árboles juveniles (fig. 2, ruta: 5 ->) ). Bajo las condiciones de sombra, estas plantas suprimen su crecimiento o crecen de manera muy lenta. La regeneración de avanzada es una comunidad que se renueva dinámicamente con procesos activos de muerte y nacimiento de plántulas. Por ejemplo, en sitios maduros de la selva de Los Tuxtlas, se observó un recambio anual del $50 \%$ de los individuos presentes en una comunidad de plántulas y árboles jóvenes, compuesta por cerca de 4,000 plantas ( $\leq 1 \mathrm{~m}$ de altura) registradas en $320 \mathrm{~m}^{2}$; este recambio incluyó la desaparición de siete especies y el ingreso de 15 especies nuevas respecto a un número original de 88 (Martínez-Ramos, 1991).

Cuando un árbol maduro cae, las semillas y la regeneración de avanzada afectadas transita a la llamada regeneración en la fase de claro (fig. 2, ruta: $4 \rightarrow 6->$ ). Existe también la posibilidad de que los troncos que resultan rotos con la caída de los árboles den lugar a rebrotes que intervienen en la regeneración en la fase de claro (fig. 2, ruta: $2 \rightarrow 9 \rightarrow$ ). Si el claro es resultado de la caída de uno o más árboles del dosel alto (claros grandes que generalmente miden más de $200 \mathrm{~m}^{2}$ de apertura en el dosel), el sitio experimenta un fuerte aumento en recursos lumínicos (Chazdon y Fetcher, 1984; Fetcher et al., 1985; Barton et al., 1989) y el suelo se enriquece en algunos nutrimentos minerales (Vitousek y Denslow, 1986; Denslow, 1987; Denslow et al., 1990). Bajo este ambiente, algunas especies son capaces de crecer rápidamente desde el estadio de semilla hasta el reproductivo en tiempos menores de cinco años (Martínez-Ramos, 1985; Sarukhán et al., 1985; Lieberman et al., 1985b; Alvarez-Buylla y Martínez-Ramos, 1992). Estas especies se han denominado pioneras por ser las que inician la colonización de los claros (Vázquez-Yanes, 1980; Swaine y Whitmore, 1988; Whitmore, 1989). Los árboles pioneros maximizan la probabilidad de arribar a un claro a través de la producción abundante de semillas pequeñas que se diseminan ampliamente (fig. 2 , ruta: $1 \rightarrow 11 \rightarrow 7 \rightarrow 8$ ). Además, algunas especies pioneras producen semillas que pueden permanecer latentes en suelo de los sitios cerrados y germinar cuando ocurre un claro (fig. 2 , ruta: $1 \rightarrow 3 \rightarrow 9 \rightarrow 7 \rightarrow 8$; Holthuijzen y Boerboom, 1982; Hopkins y Graham, 1987; Pérez-Naser y Vázquez-Yanes, 1986). De este modo, ạlgunos árboles pioneros emergen del banco de semillas presentes en sitios cerrados y otros emergen de la lluvia de semillas que cae directamente en los claros (Alvarez-Buylla y Martínez-Ramos, 1990; Denslow y Gómez-Díaz, 1990).

Las semillas de los árboles pioneros germinan estimuladas por el rico ambiente lumínico (con altos valores del cociente rojo/rojo-lejano) y las elevadas temperaturas prevalecientes en los claros (Vázquez-Yanes y Orozco-Segovia, 1984). Las plántulas 
que emergen de estas semillas mantienen una ganancia positiva de carbono sólo bajo altos niveles lumínicos de manera que mueren bajo la sombra del dosel cerrado (Bazzaz y Picket, 1980; Bazzaz, 1991). Por lo tanto, las especies pioneras ocurren de manera restringida en.los sitios del bosque donde se han abierto claros grandes (Popma et al., 1988). Por esto, la presencia de árboles pioneros identifica sitios del bosque en los que han ocurrido cambios rápidos en la estructura y composición de especies (Sarukhán et al ., 1985; Brokaw y Scheiner, 1989). Los árboles de crecimiento rápido tienen ciclos de vida cortos ( $<50$ años) y usualmente mueren en pie, con su copa y tronco fragmentándose paulatinamente (Lieberman et al., 1985a,b).

La mayoría de las especies arbóreas de selvas húmedas, sin embargo, crecen en los claros a ritmos menores a la de los árboles pioneros y requieren de varias décadas para alcanzar el estadio reproductivo (Brokaw, 1985a; Martínez-Ramos, 1985; Sarukhán et al., 1985; Alvarez-Buylla y Martínez-Ramos, 1992). Estos árboles, que por lo común presentan ciclos de vida de uno a varios siglos (Lieberman et al., 1985b), han sido denominados "persistentes" por mantenerse en el bosque como plantas maduras por largos periodos de tiempo (Swaine y Whitmore, 1988; Whitmore, 1989). En. general, estos árboles producen una cantidad menor de semillas que los pioneros. Las semillas tienden a ser de dimensiones grandes y comúnmente germinan rápidamente bajo condiciones de sombra. Las plántulas pueden mantenerse vivas bajo condiciones restringidas de luz por períodos de tiempo que varían entre las especies (Ng, 1978; Martínez-Ramos, 1991; ver también la figura 6 más adelante). La mayoría de las especies $(>75 \%$ ) de una selva húmeda posee este tipo de atributos (Hartshorn, 1978; Martínez-Ramos, 1985; Hubbell y Foster, 1986c, 1987; Denslow, 1987).

Los árboles persistentes inician su desarrollo en los claros primordialmente a partir de la regeneración de avanzada (Uhl et al., 1988). Algunas especies pueden también regenerase en los claros a través de rebrotes de árboles rotos (Putz y Brokaw, 1989). Al desaparecer los árboles pioneros, uno o varios de los árboles persistentes obtiene(n) la madurez y reemplaza(n) a aquellos que produjeron el claro (fig. 2, ruta: $6 \rightarrow 7 \rightarrow 8)$

Otra ruta de regeneración, complementaria a las anteriores, ocurre cuando se desprenden ramas grandes de los árboles maduros del dosel. El aumento de recursos lumínicos estimula el crecimiento de las plantas que se encuentran en la regeneración de avanzada pero este aumento no es suficiente para permitir el crecimiento hasta la maduración de los árboles. Algunas plántulas transitan al estadio de árbol juvenil pero quedan en ese estadio de vida dado que el nivel de recursos lumínicos disminuye rápidamente a medida que el claro se cierra con el crecimiento lateral de plantas (árboles y lianas) vecinas a los claros (fig. 2 , ruta: $6 \rightarrow 7 \rightarrow 12$ ). De este modo, las plántulas pueden avanzar hacia el estadio juvenil estimuladas por pulsos repetidos de elevada energía lumínica pero de corta duración. Es posible que algunos árboles 
juveniles pueden crecer hasta el estadio de árboles preadultos bajo condiciones limitadas de luz (fig. 2, ruta: $10 \rightarrow$ ). Estos árboles requieren, sin embargo, de un claro grande para completar el ciclo de vida (fig. 2, ruta: $4 \rightarrow 6 \rightarrow 7 \rightarrow 8$ ). Quizá los árboles que maduran en la parte baja del dosel se encuentran menos limitados por la disponibilidad de claros grandes que aquellos que maduran en el dosel superior del bosque (Martínez-Ramos 1985; Denslow, 1987).

La dinámica de las diferentes rutas de regeneración depende en una parte importante del tamaño de los claros formados (Martínez-Ramos, et al., 1988a,b). La ruta que incluye la apertura y cierre de claros pequeños $\left(\leq 50 \mathrm{~m}^{2}\right)$ se completa en tiempos relativamente cortos ( $<5$ años). Las rutas que incluyen la apertura y cierre de claros grandes $\left(\geq 100 \mathrm{~m}^{2}\right)$ pueden ser de dos tipos. Un tipo ocurre cuando un sitio con árboles pioneros recibe la caída de un árbol vecino. Este evento cierra una ruta de regeneración que podemos definir de mediano plazo dado que duraría menos de 40 años. La ruta de mediano plazo es frecuente ya que la probabilidad de que caiga otro árbol en sitios en los que han caído árboles recientemente es mayor que en otros sitios de la selva (Martínez-Ramos y Alvarez-Buylla, 1986). Si un sitio en fase de construcción no es regresado a la fase de claro, algunos de los árboles jóvenes persistentes alcanzan con el tiempo la madurez sexual, cerrando un ciclo de regeneración que podemos definir como de largo plazo ya que este ciclo tomaría más de cuarenta años en completarse (Martínez-Ramos, 1985).

Existen pocos estudios que han tratado de evaluar la frecuencia de las diferentes rutas de regeneración. En una parcela de 5 ha de la selva de los Tuxtlas, Martínez-Ramos et al. (1988a) elucontraron un 2.1\% del área ocupada por claros recientes, $33.6 \%$ por árboles pioneros (sitios en los que habían ocurido caídas de árboles 35 ó menọ años atrás) y $64.3 \%$ por árboles persistentes (sitios de más de 35 años). Durante un año promedio, el $59.4 \%$ de los claros pasaron a la ruta de largo plazo mientras que un $40.6 \%$ de los claros fueron de tamaño pequeño $\left(<50 \mathrm{~m}^{2}\right)$ y pasaron a una ruta de corto plazo. La probabilidad anual de apertura de claros (equivalente a un $2 \%$ por unidad de área) fue similar en los sitios con y sin árboles pioneros. Por último, la tasa de formación de claros fue mayor que la tasa a la que el bosque madura (es decir pierde árboles pioneros); este resultado sugiere que los árboles pioneros tienden a incrementarse en la parcela de estudio (ver detalles en Martínez-Ramos et al., 1988a).

La frecuencia relativa de las diferentes rutas de regeneración determina, en gran medida, la estructura y dinámica del bosque. La ocurrencia de las distintas rutas, a su vez, depende de un conjunto de factores exógenos y endógenos a los árboles. Entre los factores exógenos se encuentran algunos asociados al terreno (por ejemplo, topografia y características físicas de los suelos), al régimen climatológico (por ejemplo, huracanes, tormentas eléctricas, ciclones), actividad telúrica y agentes 
bióticos (herbivoros, enfermedades) que afectan el vigor de los árboles (Brokaw, 1982, 1985a; Whitmore, 1984; Lawton y Putz, 1988). Algunos de los factores endógenos incluyen: propiedades biomecánicas (Putz et al., 1983), relaciones alométricas (King, 1990; Kohyama, 1991), morfología y arquitectura de troncos y copas (Asthon, 1978; Hallé et al., 1978; Tomlinson, 1987) y propiedades químicas (que actúan como defensas en contra de enemigos naturales) de los árboles .

En regiones donde se presentan regularmente fenómenos meteorológicos severos (tales como ciclones, huracanes, deslaves y tormentas monzónicas), la elevada frecuencia de caída simultánea de muchos árboles (que llegan a abrir claros de una a varias hectáreas) produce el predominio en la selva de rutas de regeneración de mediano y una abundancia notable de árboles pioneros en la composición del bosque (Whitmore, 1984). En estos bosques el recambio del dosel es rápido. Esto también ocurre en selvas que se ven sujetas de manera frecuente a terremotos (Garwood et al., 1979). Lo contrario sucede en bosques donde la incidencia de tales agentes exógenos es rara (Hart et al., 1989). En sitios donde la incidencia de claros grandes es baja, la dinámica de regeneración de la selva se encuentra dominada por el ciclo regeneración de corto plazo. En estos bosques los árboles pioneros representan una proporción pequeña en la composición florística. Una baja frecuencia de claros grandes puede favorecer el dominio de pocas especies tolerantes a la sombra bajo un sotobosque empobrecido en luz (Ashton y Hall, 1992).

Dentro de una región que es afectada por un mismo régimen climático y telúrico, variaciones en la topografia del terreno, composición de especies del dosel, efectos de borde y estado de daño de los árboles determinan que la representación de las diferentes rutas de regeneración varíen espacialmente (Martínez-Ramos et al., 1988a; Samper, 1992). En laderas con pendiente pronunciada la caída de árboles completos es más alta que en los sitios planos y la proporción de árboles pioneros es notablemente mayor en los primeros que en los segundos (Samper, 1992; Asthon y Hall, 1992).

\section{ORGANIZACIÓN DE LA REGENERACIÓN DE AVANZADA Y SU IMPORTANCIA EN EL MANTENIMIENTO DE ESPECIES}

En general, en las selvas húmedas se forman, por unidad de área y tiempo, muchos más claros pequeños que grandes (Martínez-Ramos y Alvarez-Buylla, 1986; Lawton y Putz, 1988; Lawton, 1990). Es decir, la frecuencia de caídas de ramas y árboles que caen fragmentados es mayor que la de árboles que caen completos. Así, por ejemplo, en Los Tuxtlas aparece al menos un claro menor de $50 \mathrm{~m}^{2}$ por hectárea por año mientras que un claro mayor de $300 \mathrm{~m}^{2}$ aparece en una hectárea al menos cada 
quince años, lo que equivale a decir que un claro de estas dimensiones se forma cada año en una superficie de 15 ó más hectáreas (Martínez-Ramos et al., 1988a,b).

Los estudios en selvas altas indican que la regeneración de avanzada es la fuente principal de reemplazamiento de los árboles maduros en la mayoría de las llamadas especies persistentes (Brokaw, 1985b; Denslow, 1987; Uhl et al., 1988; Connell, 1989; Raich y Christensen 1989; Martínez-Ramos y Soto-Castro, 1993). La regeneración de avanzada se desarrolla favorecida por los pulsos temporales de luz que proveen los claros pequeños pero su maduración requiere de los espacios grandes que ocurren cuando caen árboles grandes (Martínez-Ramos, 1985; Lieberman et al., 1989).

El espacio que es dejado al caer un árbol puede ser ocupado por otro árbol de la misma o diferente especie. La probabilidad de que ocurra un reemplazo entre especies es alta si la comunidad regenerativa es diversa. Por el contrario, si la regeneración es dominada por la especie del árbol que cae, aumenta la probabilidad de un autoreemplazo. Dado que las especies persistentes conforman la mayor parte de la comunidad arbórea de una selva alta perennifolia (Harthsorn, 1978), es de esperarse que el entendimiento de cómo se mantiene la diversidad de especies de árboles descansa en gran parte en entender: i) cómo se estructura la regeneración de avanzada y ii) cómo se relaciona la estructura de la regeneración de avanzada con la dinámica reemplazamiento de árboles.

\section{Estructuración de la Regeneración de Avanzada}

La figura 3 muestra un diagrama que señala la ruta seguida por las especies, que llegan al piso de la selva madura en forma de semillas, hacia su integración en la regeneración de avanzada. Para describir la estructura de la comunidad usaremos dos parámetros: la riqueza de especies (número de especies presentes) y la abundancia relativa de las especies. Estas son variables que son importantes para entender la relación entre la regeneración de avanzada y el mantenimiento de la diversidad de árboles del dosel, como se describe más adelante.

Considerando que estamos interesados en analizar el reemplazo de árboles en un punto dado de la selva, podemos restringir el análisis de la estructuración de la regeneración de avanzada a una superficie equivalente al área ocupada por la copa de un árbol del dosel alto (aproximadamente $10 \mathrm{~m}$ de radio de copa si suponemos a esta como de forma circular). A tal área la podemos definir como un parche maduro (fig. 3). Entonces, lo importante es caracterizar la estructura de la comunidad de plántulas y árboles jóvenes presente bajo la copa de este árbol y escudriñar los procesos y mecanismos que intervienen en definir tal estructura: ¿es igual para todas las especies la posibilidad de establecerse y persistir en la regeneración de avanzada? 


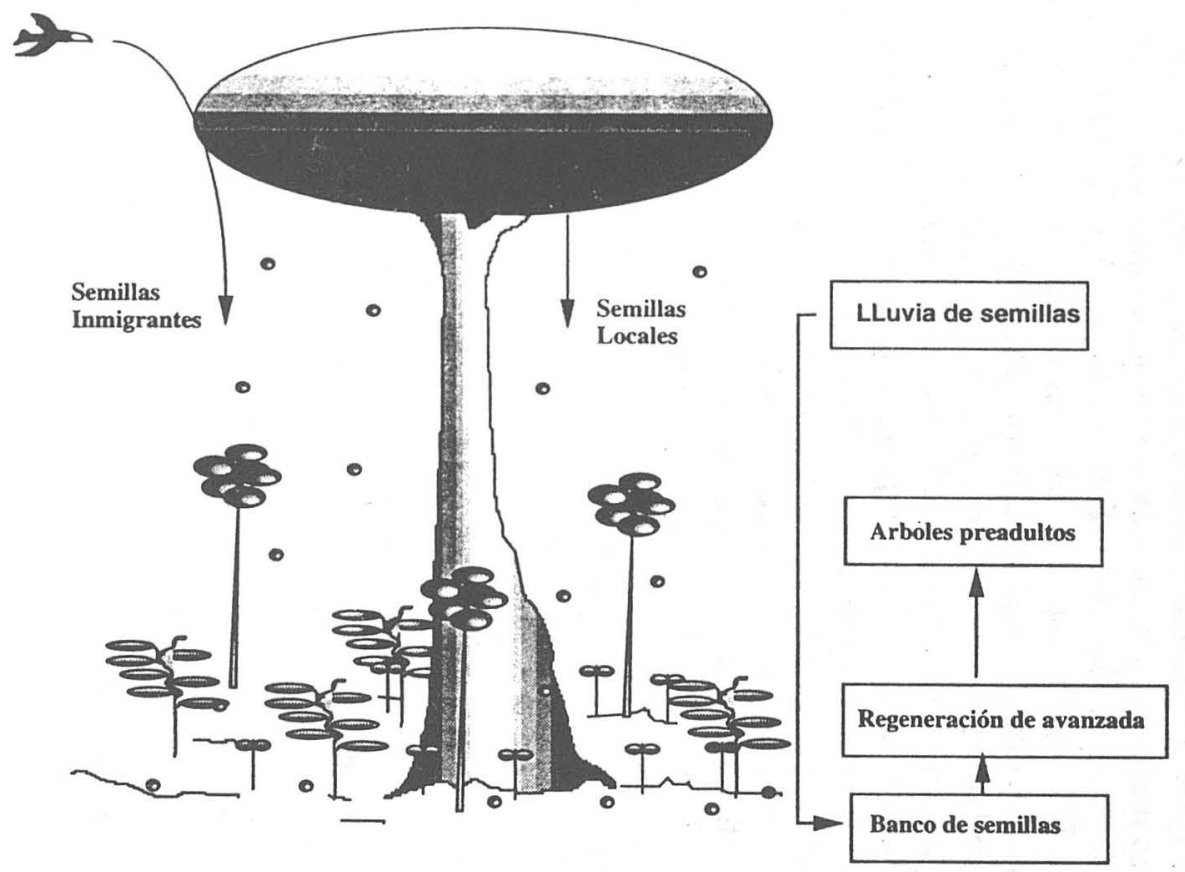

Factores que afectan la estructura de la comunidad

Fenología, atracción a frugivoros

\section{Funciones cotidelonarias de las plántulas, herbivoros, patógenos, daños físicos, tolerancia a la sombra}

\section{Depredación, patógenos,} agentes abióticos que afectan la viabilidad de las semillas

Fig. 3. Idealización de un parche maduro y los componentes y factores que intervienen en la estructuración de la comunidad de plantas encontradas en la regeneración de avanzada (ver texto para más detalles). 


\section{i. Lluvia de semillas}

La riqueza de especies presente en la lluvia de semillas que ingresa al suelo en un parche maduro (fig. 3) depende de dos componentes: i) el de las semillas producidas por los árboles presentes en el parche (semillas "locales") y, ii) el aportado por la dispersión de semillas producidas por árboles que crecen fuera del parche (semillas "inmigrantes") (Martínez-Ramos y Soto-Castro, 1993). La llegada de estas últimas depende de los agentes de dispersión de semillas. En las selvas húmedas, algunas especies producen diásporas que son transportadas por el viento (Augspurger, 1986; Augspurger y Franson, 1988; Ibarra-Manríquez et al., 1991) pero la mayoría de las especies producen diásporas que son transportadas por aves y mamíferos frugivoros (Estrada y Fleming, 1986; Fleming y Estrada, 1993). A nivel de la comunidad de árboles, más del $70 \%$ de las especies arbóreas producen frutos cuyas estructuras morfológicas sugieren dispersión por frugívoros (Jackson, 1981; Janson, 1983; Foster y Janson, 1985; Foster, 1990; Ibarra-Manríquez y Oyama, 1992). Dado que dentro del parche existe un número reducido de árboles maduros (uno del dosel alto pero otros de doseles inferiores), las semillas inmigrantes son las que determinan en mayor medida la riqueza de especies presente en la lluvia de semillas (fig. 3). Sin embargo, las especies inmigrantes son mucho menos abundantes que las semillas producidas localmente (Martínez-Ramos y Soto-Castro, 1993).

Debido a diferencias entre las especies en la fenología de producción de frutos (Frankie et al., 1974; Janzen, 1978; Carabias y Guevara, 1985; Wheelwright, 1986; Yap y Chan, 1990; Newstrom et al., 1994), la composición y riqueza de especies presentes en la lluvia de semillas puede variar temporalmente. Considerando un ciclo anual, sin embargo, es posible cubrir la representación de especies que fructifican en diferentes meses del año. Durante un ciclo anual, en Los Tuxtlas se registraron entre 43 a 50 especies en la lluvia de semillas ocurrida en cinco parches maduros; las semillas inmigrantes (dispersadas por frugívoros) representaron entre $56 \%$ y $80 \%$ de la riqueza de especies por parche (Martinez-Ramos y Soto-Castro, 1993).

Los datos anteriores muestran la gran importancia de los frugívoros como generadores de diversidad. La variación en la proporción de especies inmigrantes puede reflejar que la actividad de los frugívoros varía entre diferentes parches. Por ejemplo, aquellos árboles que producen frutos carnosos ricos en azúcares, tales como los de muchas especies de Ficus y Cecropia, atraen a un gremio diverso y abundante de aves y mamíferos frugívoros (Howe y Estabrook, 1977; Estrada, 1984; Estrada et al., 1984; Guevara y Laborde, 1993). En contraste, los árboles que producen frutos ricos en lípidos atraen a un número restringido de especies frugivoras especializadas en manejar y consumir tal tipo de frutos (Howe y Estabrook, 1977; Wheelwright, 1985, 1993; Howe, 1990a; Martínez del Río y Restrepo, 1993). La lluvia de semillas que cae bajo los árboles que no producen frutos carnosos ni semillas ariladas (como 
aquellos que dispersan sus semillas a través del viento) debería mostrar una riqueza de especies aún menor dado que se esperaría que estos árboles no fuesen atractivos para los animales frugivoros.

Un caso interesante, en relación con el punto anterior, es el de las especies cuyos árboles maduros tienen sexos separados. En especies dioicas que producen frutos carnosos, la lluvia de semillas que cae bajo los árboles femeninos debería mostrar una mayor riqueza de especies que aquella que cae bajo la copa de árboles masculinos que solo producen polen. Un análisis de la estructura de la comunidad de plántulas (plantas $0.5 \mathrm{~cm}$ de altura) bajo árboles maduros de Brosimum alicastrum y Pseudolmedia oxyphyllaria (Moraceae) mostró que la riqueza de especies bajo los árboles femeninos fue tres veces mayor que aquella registrada bajo los masculinos $(0$. Meza, datos no publicados).

ii. Transición de las especies de la lluvia de semillas a la comunidad de plántulas.

La mayoría de las especies arbóreas de selvas húmedas producen semillas que germinan rápidamente, muchas en periodos menores a tres meses $(\mathrm{Ng}, 1978$; Garwood, 1983, 1989; Vázquez-Yanes y Orozco-Segovia, 1984, 1993). La posibilidad que tiene una especie representada en la lluvia de semillas de transitar a la comunidad de plántulas depende de factores que afectan la viabilidad de las semillas y su eventual germinación. Factores abióticos como el pH, la humedad del suelo y la relación rojo/rojo-lejano son controladores de la viabilidad de las semillas y/o de su germinación (Vázquez-Yanes y Orozco-Segovia, 1993). Algunas especies no transitan al estadio de plántula en los parches maduros ya que sus semillas no germınan bajo las condiciones abióticas que operan en tales sitios. Por ejemplo, la emergencia de plántulas de especies fotoblásticas, como Cecropia obtusifolia y varias especies de Piper, tienen baja probabilidad de germinar bajo doseles cerrados de la selva, donde la relación rojo/rojo-lejano tiene valores reducidos (Vázquez-Yanes y Orozco-Segovia, 1993). También la ausencia de fuertes variaciones de temperatura en el suelo de los parches maduros no permiten la germinación de especies termoblásticas como aquellas de Heliocarpus (Vázquez-Yanes y Orozco-Segovia, 1993).

La mayoría de las especies, sin embargo, producen semillas recalcitrantes que pueden germinar en los parches maduros (Vázquez-Yanes y Orozco-Segovia, 1984, 1993). Quizá más importante que las condiciones abióticas para la sobrevivencia de estas semillas son los insectos, microorganismsmos y vertebrados que las depredan (Dirzo y Domínguez, 1986). Janzen $(1969,1971)$ documentó niveles de mortalidad de semillas en muchas especies que rebasan con frecuencia el $90 \%$ de la cosecha producida por un árbol. En los Tuxtlas, las semillas de la palma Astrocaryum mexicanum sufre un $95 \%$ de depredación, causada principalmente por roedores y ardillas (Sarukhán, 1980). Aún las pequeñas semillas del árbol Cecropia obtusifolia 
sufren una mortalidad mayor del $90 \%$ debido al ataque de hormigas y ortópteros (Alvarez-Buylla y Martínez-Ramos, 1990).

Existen también especies que tienen bajo riesgo de depredación de semillas (Terborgh et al., 199.3). Por ejemplo, en los Tuxtlas, las semillas de Omphalea oleifera virtualmente no son atacadas (Palomeque, 1988). Otras especies más sufren niveles intermedios de depredación. La figura 4a muestra un histograma de distribución de frecuencia de valores porcentuales de remoción de semillas que se observaron bajo condiciones naturales en 43 especies arbóreas encontradas en diferentes bosques húmedos tropicales; los datos fueron recopilados de la literatura por Rodríguez (1994). Puede notarse que aunque existe un sesgo hacia valores de remoción elevados, la variación entre especies cubre todo el ámbito posible de valores de remoción. Los diferentes niveles de depredación pueden radicar en que las semillas de diferentes especies difieren en estructuras fisicas y químicas que pueden resultar defensas efectivas o pobres contra la depredación (Janzen, 1969; Dirzo, 1987).

$\mathrm{La}$ variación también puede deberse a que los depredadores seleccionan semillas de diferentes calidad nutricional. Las especies difieren en el contenido de cárbohidratos, lípidos o proteínas que las semillas almacenan para ser utilizadas por las plántulas. La cantidad de tales reservas aumenta con el tamaño de las semillas (Fenner, 1985; Howe y Ritcher, 1982) por lo que es de esperarse que la depredación ocurra con mayor intensidad sobre las semillas grandes. Los vertebrados que consumen semillas localizadas en el suelo tienden a depredar a aquellas que ofrecen mayor cantidad de recursos. En Los Tuxtlas, un experimento que llevó a cabo la exclusión de vertebrados terrestres indicó que estos animales tienden a depredar con mayor intensidad a las semillas de especies que producen semillas grandes (fig. 4b).

La conducta de búsqueda de semillas de los depredadores también puede influir en las posibilidades que tiene una especie de transitar del estadio de semilla al de plántula. Algunos depredadores tienden a concentrar su ataque en la vecindad de la planta progenitora o en áreas donde la densidad de semillas es mayor (Janzen, 1970; Clark y Clark, 1984; Schupp, 1988a,b). Entre los primeros, son más comunes animales vertebrados que poseen alta capacidad de aprendizaje. Entre los segundos, son más comunes insectos y microorganismos patógenos que atacan a las semillas cuando aún se encuentran en la planta materna y que pueden también infestar a las semillas que ya han caido al suelo. Es esperable que la depredación dependiente de la densidad, o de la distancia a la planta progenitora, reduzca en mayor grado la abundancia de las semillas de producción local que la de semillas inmigrantes.

La producción abundante de semillas de los árboles maduros que dominan un parche puede, sin embargo, facilitar que muchas semillas locales transiten al estadio de plántulas aún cuando el nivel depredación sea intenso (Hubbell, 1979). Por ejemplo, un árbol de Nectandra ambigens (Lauraceae) produce alrededor de 300,000 semillas 
(a)
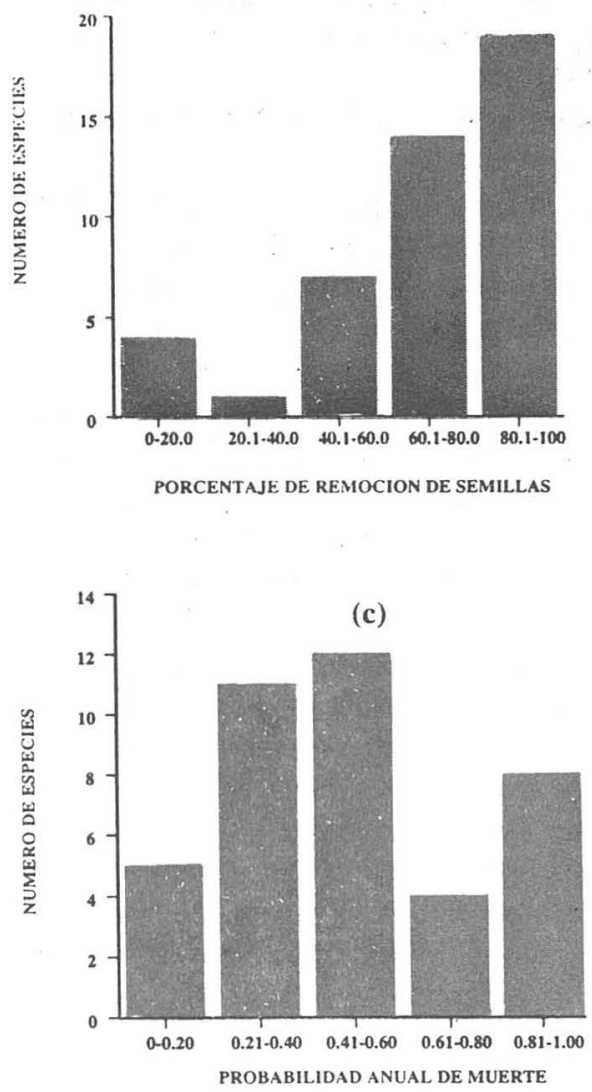

(b)

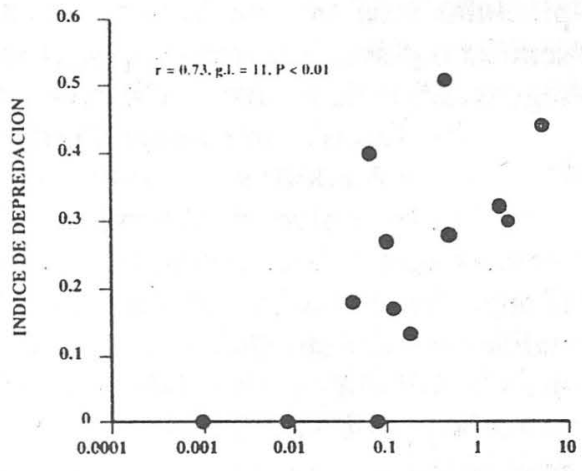

PESO SECO PROMEDIO DE SEMILLAS (gr)

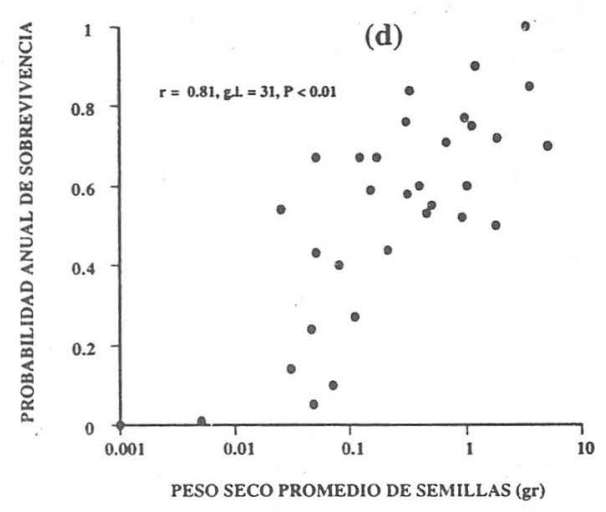

Fig. 4. Aspectos de mortalidad en la comunidad de semillas y plántulas en parches maduros de selva húmeda. a) Variación en las tasas de remoción de semillas observadas para 43 especies arbóreas en diferentes selvas húmedas neotropicales (Rodríguez, 1994). b) Susceptibilidad de depredación de semillas por vertebrados terrestres como función del tamaño de la semillas (note escala logarítmica) en Los Tuxtlas, Veracruz; cada punto representa una especie (modificado de Martínez-Ramos, 1991). c) Variación interespecífica en las tasas de mortalidad de plántulas ( $\mathrm{n}=44$ especies) observadas en Los Tuxtlas, Veracruz (M. Martínez-Ramos, dátos no publicados). d) Relación comunitaria de la sobrevivencia de plántulas recién nacidas como función del tamaño de las semillas en Los Tuxtlas, Veracruz; cada punto representa una especie (modificado de Martínez-Ramos, 1991). 
per cosecha y sufre un 50\% de depredación (Córdova, 1985). En consecuencia, en un parche maduro dominando por esta especie se reclutan alrdedor de 3 plántulas por metro cuadrado (Martínez-Ramos, 1991). Tal densidad es mucho mayor a la densidad de plántulas exhibida por especies inmigrantes, la mayoría representada por pocas plántulas (con frecuencia por sola una) dentro de todo el parche. La muerte de una semilla o plántula de tales especies inmigrantes puede determinar su exclusión de la regeneración de avanzada (Martínez-Ramos, 1991).

iii. Transición de especies desde la comunidad de plántulas a la de árboles preadultos.

El bajo nivel de recursos lumínicos disponibles a las plántulas y los árboles jóvenes que se encuentran en un parche maduro limita seriamente su desarrollo (Langenheim et al., 1984; Chazdon, 1988a; Popma y Bongers, 1988). Del total de la radiación solar que incide sobre el dosel más alto de una selva, solamente alrededor del $1 \%$ al $5 \%$ llega al nivel del suelo (Chiarello, 1984). La apertura frecuente de claros pequeños posibilita aumentos de luz en el sotobosque y el crecimiento de las plantas encontradas en la regeneración de avanzada (Clark y Clark, 1987; Chazdon, 1988a).

El efecto limitante de los bajos niveles de luz sobre la vegetación del sotobosque son notorios. Por ejemplo, en Los Tuxtlas, el 50\% de la superficie del suelo esta desprovisto de vegetación ( $<1 \mathrm{~m}$ de altura) en los sitios maduros que presentan baja disponibilidad lumínica a nivel del suelo. La cubierta vegetal en esos sitios estuvo dada principalmente $(>75 \%$ ) por plantas no arbóreas (principalmente herbáceas) que parecen tolerar muy bien la sombra (Martínez-Ramos, 1991). En otros sitios, donde llegan al suelo haces de luz directa, que se filtran por pequeños claros del dosel, se encuentra una mayor abundancia de plantas ( $<1 \mathrm{~m}$ de altura) que llegan a formar hasta dos capas de follaje por unidad de área de terreno (Martínez-Ramos, 1991). En los claros grandes tal vegetación se desarrolla aún más vigorosamente (Dirzo et al., 1992).

Para sobrevivir y crecer, los productos fotosintéticos de una planta deben cubrir sus gastos metabólicos respiratorios. Estos gastos tienen que ver con: i) el mantenimiento de los tejidos que ya constituyen a la planta, ii) con la renovación de tejidos y la reparación de tejidos dañados y iii) con la formación de nuevos tejidos durante el proceso de crecimiento. Si la cantidad de energía y carbono ganados por fotosíntesis no es suficiente para compensar los gastos realizados para mantener los tejidos ya formados entonces la planta muere. Si estos gastos son compensados pero no existe una cantidad de energía excedente entonces la planta podría morir si es dañada y no es capaz de reponer los tejidos dañados o perdidos. Si existe una cantidad de fotosintetatos excedente a la reparación de tejidos dañados, o no existen tales daños, entonces la planta puede crecer.

En las selvas húmedas las plántulas y árboles jóvenes son dañados (perdiendo parte o la totalidad de la superficie foliar y meristemos de crecimiento) por la caida 
frecuente de ramas, frutos, hojas y frondas grandes de palmas (Vandermeer, 1977; Aide, 1987; Clark y Clark, 1989, 1991; Vázquez-Yanes et al., 1990; Molofsky y Augspurger, 1992). En Los Tuxtlas, se encontró que un punto del suelo en parches maduros recibe cada dos años al menos un golpe ocasionado por una rama de 5 a $15 \mathrm{~cm}$ de diámetro (M. Martínez-Ramos, datos no publicados). Por esto, la posesión de estructuras morfológicas y anatómicas (́como tallos robustos y flexibles y abundante cantidad de meristemos) que permitan a las plantas resistir o recuperarse de los daños fisicos deben favorecer la persistencia de una especie en la regeneración de avanzada (DeStevens, 1989).

Los animales herbívoros causan también pérdidas de tejido foliar (De la Cruz y Dirzo, 1988) las cuales reducen la habilidad de las plántulas para capturar luz (Howe, 1990b). Bajo condiciones de sombra, niveles de herbivoría reducidos pueden causar la muerte de las plántulas (Dirzo, 1984; Careaga, 1989; Howe, 1990b). Microorganismos (hongos, virus, bacterias) patógenos también pueden causar serios daños que conducen a la pérdida de tejido foliar o al deterioro total de las plántulas (Augspurger, 1984a; Augspurger y Kelly, 1984). Parte de los gastos respiratorios asignados al mantenimiento de los tejidos son usados en la formación de estructuras físicas o químicas que defienden a las plantas de los herbívoros y patógenos (Coley 1983; Coley et al., 1985; Bazzaz et al., 1987; Bazzaz y Ackerly, 1992). Entonces, la capacidad de una planta para crecer bajo una condición dada de luz depende de su habilidad para obtener un balance positivo entre la ganancia absoluta de carbono por fotosíntesis y los gastos de energía y carbono ocasionados por la respiración.

Entre las especies arbóreas existe una fuerte variación en la capacidad que poseen las plántulas y árboles jóvenes para mantener tasas netas positivas de asimilación de carbono bajo condiciones limitadas de luz (Popma y Bongers, 1988; Strauss-Debenedetii y Bazzaz, 1991). Esto se traduce en una variación interespecífica importante en la sobrevivencia de las plántulas en los parches maduros (Augspurger, 1984b). Entre los extremos, existen especies como Cecropia obtusifolia cuyas plántulas no sobreviven en absoluto bajo condiciones de sombra (Alvarez-Buylla y Martínez-Ramos, 1992) y aquellas de la palma Astrocaryum mexicanum que logran sobrevivir por varios años en tales condiciones (Piñero et al., 1984). Entre las especies cuyas plántulas son estrictamente demandantes de luz y aquellas que pueden sobrevivir en la sombra, existen muchas con rendimientos intermedios. La figura $4 \mathrm{c}$ muestra la variación interespecífica observada en la probabilidad de muerte que experimentaron plántulas recién nacidas durante su primer año de vida en parches maduros. En promedio, las plántulas tuvieron una probabilidad de muerte anual igual a 0.43. Sin embargo, esta probabilidad varió notablemente entre las especies. Así, aunque en el $37 \%$ de las especies las plántulas sufrieron tasas de mortalidad menores al $40 \%$, existió un buen número de especies (28\%) con tasas mayores al $60 \%$.

Un alto contenido de recursos maternos en las estructuras de las semillas puede 
permitir a las plántulas sobrevivir por algún tiempo bajo condiciones lumínicas limitantes (Howe y Ritcher, 1982; Fenner, 1985; Foster, 1986; Oberbauer, 1990). Por ejemplo, la figura 4d ilustra que, a nivel de la comunidad, la sobrevivencia anual de plántulas recién nacidas aumenta significativamente con el tamaño de las semillas (presumiblemente un indicador de la cantidad de reservas maternas por plántula). En la sombra, las especies cuyas plántulas que poseen cotiledones y/o endospermo que funcionan como órganos de almacenamiento de reservas maternas tienen mayor posibilidad de persistir en la regeneración de avanzada que las especies cuyas plántulas tienen cotiledones que funcionan como órganos fotosínteticos (Ng, 1980; Foster, 1986; Hladik y Miquel, 1990; Martínez-Ramos y Soto-Castro, 1993). En contraparte, sin embargo, las especies que tienen semillas pequeñas poseen una mayor capacidad de ocupar un número mayor de parches que las especies que tienen semillas grandes dada su mayor vagilidad. En efecto, González-Méndez (1994) encontró una clara relación negativa entre la distancia máxima de dispersión y el tamaño de las semillas en un grupo de 13 especies cuyo tamaño de semilla (peso seco) varía en siete órdenes de magnitud. Las especies con semillas pequeñas compensan su bajas probabilidades de persistir en la regeneración avanzada de un parche con el ingreso en muchos; las especies de semillas grandes tienen altas posibilidad de persistir en la regeneración de avanzada de un parche pero pobre capacidad de desplazarse a otros.

Los mismos factores abióticos y bióticos de mortalidad que operan a nivel de las plántulas también actuan sobre los árboles juveniles (cf. fig. 3). Quizá, sin embargo, en estos últimos la frecuencia de muerte causada por daños fisicos es mayor que aquella causada por agentes bióticos (Clark y Clark, 1991). En árboles jóvenes de Pseudolmedia oxyphyllaria y Trophis mexicana no se detectaron daños importantes de herbívoros y patógenos pero un porcentaje considerable de ellos (20-30\%) presentaban tallos rotos, debido a golpes recibidos por la caída de ramas y árboles (M. Martínez-Ramos et al., datos no publicados). En la palma Astrocaryum mexicanum más de un tercio del total de los individuos con tallo que murieron durante un lapso de 4 años se debió a daños causados por la caída de objetos del dosel (Piñero et al., 1984). En Dipterix panamensis una proporción mayoritaria de los árboles juveniles que murieron durante ocho años se debió a daños físicos (Clark y Clark, 1987, 1991).

Como se describió para las semillas, la abundancia de las plántulas y juveniles de cada especie puede ser importante en la posibilidad que tiene una especie de persistir en la regeneración de avanzada. En general, las especies más raras tienen mayor riesgo de extinguirse que las más abundantes (Martínez-Ramos, 1991).

En resumen, el arribo de la mayoría de las especies a la regeneración avanzada de debe en gran parte a la actividad de frugívoros. Las especies cuyas semillas producen plántulas robustas, que poseen órganos que almacenan grandes cantidades de reservas maternas y que tienen la capacidad de reparar daños fisicos y bióticos bajo 
condiciones limitadas de luz tienen mayor posibilidad de persistir en la regeneración de avanzada. Las especies cuyas semillas dan lugar a plántulas pequeñas con cotiledones fotoblásticas tienen mayor riesgo de desaparecer de tal comunidad. Sin embargo, estas especies pueden ingresar a una mayor cantidad de parches que las especies con tamaños de semillas grandes. Este tipo de disyuntivas son importantes en mantener diversidad en la regeneración de avanzada.

\section{REEMPLAZO DE ÁRBOLES Y MECANISMOS MANTENIMIENTO DE LA DIVERSIDAD}

¿En qué medida los eventos históricos, estocásticos y ecológicos favorecen el mantenimiento de la diversidad? Esta pregunta se ha abordado con hipótesis que pueden dividirse en dos grandes grupos (Chesson y Casse, 1986). Un grupo de hipótesis, que se relaciona con la llamada "teoría clásica" de la competencia, propone que las especies coexisten porque el crecimiento poblacional de las especies es regulado por fenómenos de competencia intraespecífica. Tal regulación debería mantener a las poblaciones por debajo de los umbrales de densidad en las que ocurririan fenómenos de exclusión competitiva entre especies. De operar tales mecanismos, se predice la evolución de especies con nichos restringidos y específicos y el desarrollo de comunidades fuertemente organizadas. Dada tal especifidad en los nichos de cada especie, se esperaría que después de una perturbación estas comunidades podrían regresar a la estructura existente antes de la perturbación.

Otra hipótesis pone como factor de regulación de las poblaciones y como elemento clave de la coexistencia a organismos depredadores. La hipótesis propone que muchas especies competidoras (presas) pueden coexister si la tasa de depredación que opera sobre ellas determina que los recursos usados por las presas no se agoten. Dicho de otra manera, la coexistencia puede facilitarse si los depredadores actuan de manera más intensa sobre las especies más abundantes, presumiblemente las que poseen mayor habilidad competitiva (Connell et al., 1984).

El otro grupo de hipótesis, llamadas de "no equilibrio", considera que las poblaciones tienen una dinámica que es gobernada por fenómenos azarosos, tales como disturbios físicos y bióticos. Un disturbio ocasiona una reducción importante en la densidad de la población y permite que los recursos aumenten en su disponibilidad. Después de un disturbio las poblaciones pueden crecer rápidamente pero la ocurrencia de nuevos disturbios mantienen a las poblaciones por debajo de la densidad que genera competencia entre especies. De esta manera, las poblaciones fluctuan en su densidad de manera impredecible (Chesson y Casse, 1986). En el escenario de deriva 
comunitaria propuesto por Hubbell y Foster (1986b), la coexistencia de especies es una consecuencia del balance entre las tasas de extinción e inmigración determinadas por eventos de azar e historia (ver páginas anteriores) y no por la interacción entre las especies. Esta hipótesis sugiere la interacción difusa de especies y un recambio aleatorio entre ellas que resultaría en: i) la evolución de gremios de especies que poseen historias de vida comunes que convergen hacia amplias zonas adaptativas y ii) en comunidades con una estructura laxa, cambiante (a través del espacio y del tiemo), que despues de una perturbación no regresan a su estructura original (Hubbell y Foster, 1991).

Tomando como marco de referencia a las hipótesis anteriores, quisiera centrar el último punto de la presente revisión y que se refiere a la relación entre el reemplazo de árboles y los mecanismos ecológicos (poblacionales y comunitarios) que facilitan el mantenimiento de la diversidad a una escala local. Para analizar tal relación, establezco que la diversidad de especies observada en la comunidad de árboles maduros es el producto de los procesos que ocurren durante el desarrollo de las comunidades pre-maduras, desde el de semillas hasta la de árboles pre-adultos. Dada la gran mortalidad de los árboles que ocurre durante sus estadios de vida pre-adultos y las bajas tasas de mortalidad que operan a nivel de los árboles adultos (Sarukhán, 1980; Lieberman et al., 1985a; Hubbell y Foster, 1990a; Alvarez-Buylla y Martínez-Ramos, 1992), es esperable que, en gran medida, la organización de la comunidad de árboles del dosel ocurra precisamente en los estadios pre-adultos. A diferencia de Hubbell y Foster (1986b), que desarrollaron su hipótesis de la deriva comunitaria observando patrones estructurales de la comunidad de árboles maduros (dap $>20 \mathrm{~cm}$ ), mi planteamiento es que para entender cómo se mantiene la diversidad en el dosel es necesario considerar a los patrones y procesos que ocurren en la regeneración de avanzada y aquella que ocurre en los claros. El punto medular es establecer en que medida los factores aleatorios y los mecanismos de equilibrio favorecen (o impiden) el reemplazo de especies en el dosel.

De antemano creo que existe suficiente evidencia que apoya un cierto nivel de diferenciación ecológica entre grandes grupos de especies; por ejemplo, pueden reconocerse grupos de especies que sólo crecen en los claros, algunos en diferentes tamaños de claros (Brokaw, 1987), grupos de especies que pueden encontrarse en todas las fases regenerativas del mosaico de la selva (Chazdon et al., 1988; Williams et al., 1989), grupos de especies que ocupan diferentes habitats topográficos o edáficos (Hubbell y Foster, 1986c; Becker y Castillo, 1990) y grupos de especies que maduran a distintos niveles del dosel (Chazdon, 1985, 1988b; Hubbell y Foster, 1986c; Martínez-Ramos, 1991). También existe evidencia de que algunas especies están sujetas a fenómenos ecológicos dependientes de la densidad que pueden regular a sus poblaciones (Martínez-Ramos et al., 1988a; Hubbell y Foster, 1990c; Condit et al., 1992, 1994; Alvarez-Buylla, 1994). Por lo tạto, creo que las hipótesis de 
diferenciación ecológica son parcialmente ciertas. Sin embargo, el punto al que quisiera enfrentar es entender el cómo se mantienen las especies que pueden ubicarse dentro de estos grandes grupos o "gremios" ecológicos.

Bajo una hipótesis de equilibrio, la abundancia que tiene una especie actua como un factor negativo en la probabilidad de persistir en la regeneración de avanzada y en última instancia de alcanzar el dosel (fig. 5a). La mortalidad de semillas y plántulas sería más intensa en las especies locales y menor en las inmigrantes ya que la abundancia de las primeras es mucho mayor que el de las segundas. Como consecuencia, la diversidad en la regeneración de avanzada debería ser alta y la probabilidad de que ocurran reemplazos entre árboles heteroespecíficos debería ser elevada. En este sentido, los mecanismos ecológicos que regulan la abundancia relativa de las especies en la regeneración de avanzada serían clave para el mantenimiento de la diversidad de especies en el dosel.

Existe la posibilidad, al menos en teoría, de que la intensidad de mortalidad sea mayor sobre las especies raras (es decir, las inmigrantes; fig. 5b). Esta situación daría lugar a una regeneración de avanzada dominada por la progenie de los árboles maduros que ocupan estos parches y como consecuencia una disminución de la diversidad en la regeneración de avanzada y una alta probabilidad de reemplazos coespecíficos.

Bajo la hipótesis de no equilibrio, se esperaría una situación similar a la anterior aunque el mecanismo sería distinto. Las semillas producidas por los árboles que dominan un parche tendrían una abundancia mayor a la de muchas especies inmigrantes. Si la probabilidad de transitar de un estadio a otro (de semilla a plántula, de plántula a juvenil) fuese mediado por fenómenos independientes de la abundacia de las especies (esto es que la probabilidad de muerte fuese la misma para todas las especies), se esperaría que la diversidad se mantuviera igual o declinara ligeramente desde la comunidad de semillas a la de árboles jóvenes (fig. 5c). De este modo el dominio de las especies más abundantes se mantiene al momento de la apertura de un claro y la probabilidad de reemplazos coespecíficos debería ser alta. En tal caso, cada especie tendería a mantener los parches ya ocupados. Entonces, la colonización de nuevos parches debería depender de eventos de oportunidad generados por eventos catastróficos (fuegos, huracanes, terremotos, deslaves) que eliminan la regeneración de avanzada y facilitan la colonozación de nuevas especies. El escenario anterior sería asociable a la hipótesis de deriva comunitaria de Hubbell y Foster (1986b).

La existencia de mecanismos que facilitan la diversidad en la regeneración de avanzada es sugerida por la gran diversidad de especies que se ha registrado (a la escala de unos cuantos metros cuadrados) en la comunidad de plántulas y árboles juveniles que crecen bajo doseles cerrados. Dirzo y Miranda (1991) encontraron, en promedio, 2.3 especies de plántulas (plantas $\leq 50 \mathrm{~cm}$ de altura) por metro cuadrado en Los Tuxtlas y $6.7 \mathrm{~m}^{2}$ en Chajul, Chiapas. En Los Tuxtlas, un censo de 320 cuadros 


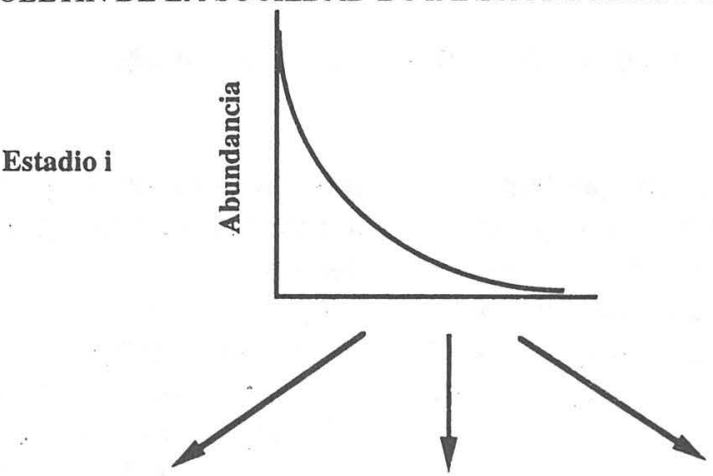

(a)

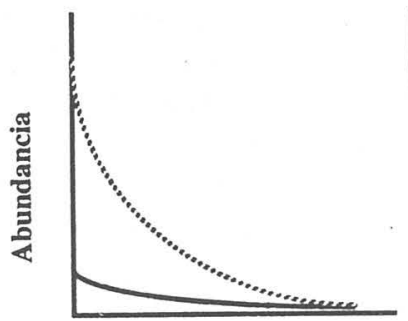

(b)

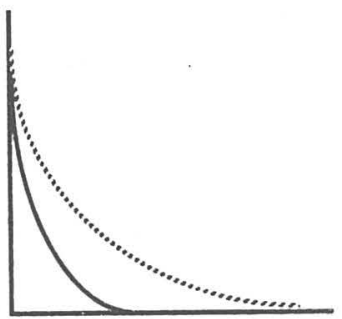

Orden de abundancia de las especies

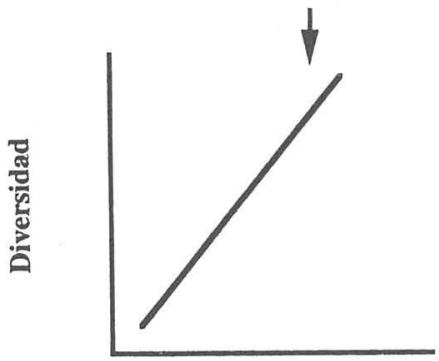

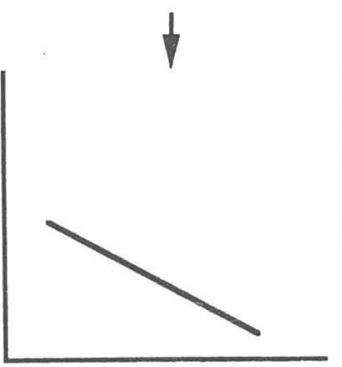

Estadio de vida (c)

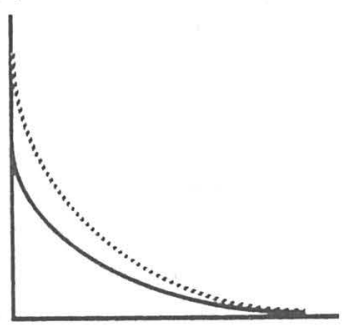

Fig. 5. Posibles efectos de factores de mortalidad dependientes de la frecuencia sobre la estructura de la comunidad representada por la regeneración de avanzada. En la parte superior se ilustra una curva dominancia-diversidad (Magurran, 1988) asignable a una comunidad de plantas encontradas en un estadio de vida i (por ejemplo, semillas). Esta curva expresa un cierto valor de diversidad de especies (medida por el número de especies y la abundancia relativa entre ellas). Cuando esta comunidad transita a otros estadios de vida (por ejemplo, plántulas) la diversidad puede modificarse de tres maneras: a) aumentar, por efecto de factores de mortalidad que actúan con mayor intensidad sobre las especies más abundantes, b) disminuir, por efecto de factores que operan en mayor medida sobre las especies menos abundantes y c) mantenerse o declinar ligeramente, si los factores de mortalidad operan independientemente de la abundancia de las especies. 
de $1 \mathrm{~m}^{2}$, distribuidos a través de varios parches maduros, arrojó un registro de 3,717 plántulas (equivalente a una densidad promedio de 11.6 plántulas por metro cuadrado), que representaron a 87 especies arbóreas. Cerca de la mitad de las especies registradas provinieron a través de la dispersión de semillas de árboles que no se encontraban dentro de los sitios de estudio (Martínez-Ramos y Soto-Castro, 1993). La riqueza de especies de plántulas por metro cuadrado fue alta ya que más del $50 \%$ de los cuadros censados presentaron más de tres especies y cerca del un $10 \%$ de los cuadros presentaron más de seis especies. En Finca La Selva, Costa Rica, se han encontrado valores similares de diversidad en la regeneración de avanzada (Marquis et al., 1986).

¿Qué evidencia existe en fayor de los escenarios de equilibrio y no equilibrio? Respecto al escenario de equilibrio, varios estudios han mostrado que agentes bióticos de mortalidad de semillas y plántulas actuan con mayor intensidad bajo la copa de los árboles progenitores que lejos de ellos, en gran concordancia con las hipótesis de Janzen (1970) y Connell (1971); (ver también Clark y Clak, 1984; Schupp, 1988a,b). Se ha detectado una mayor mortalidad de árboles juveniles en las cercanías de árboles coespecíficos que lejos de ellos (Clark y Clark, 1984; Hubbelly Foster, 1990b; Condit et al., 1992, 1994). Por ejemplo, Ocotea whitei (Lauraceae) exhibe un notable espaciamiento entre los jueveniles y los adultos que es causado por una enfermedad que causa úlceras en los troncos y que infecta (y mata) con mayor incidencia a los juveniles cercanos a los árboles adultos infectados (Gilbert et al., 1994). En Australia, Connell et al. (1984) encontraron que la diversidad de especies de la comunidad de plántulas presente en sitios maduros es regulada por factores de mortalidad que operan sobre las especies más comunes. Este mismo fenómeno fue observado en Los Tuxtlas (Martínez-Ramos, 1991). Un estudio experimental de exclusión de vertebrados terrestres mostró que en ausencia de estos animales la diversidad de árboles menores a $1 \mathrm{~m}$ de altura disminuyó dramáticamente debido a que la tasa de reclutamiento de plántulas de especies locales aumenta en varios ordenes de magnitud en ausencia de mamíferos depredadores de semillas y plántulas (fig. 6a). Las especies más abundantes aumentaron aún más su abundancia en ausencia de los vertebrados mientras que las especies menos abundantes no mostraron ningún cambio significativo. De esta manera, bajo condiciones naturales, en la comunidad de plántulas las especies más abundantes declinaron de un año a otro mientras que las especies menos abundantes incrementaron su abundancia (fig. 6b). En Los Tuxtlas también se observó que la diversidad de especies, y la uniformidad en la abundancia relativa entre las especies, es mayor en la comunidad de árboles juveniles que en aquella registrada en la de plántulas y en la lluvia de semillas (fig. 6c; Martínez-Ramos y Soto-Castro, 1993).

También existe evidencia a favor de las hipótesis de no equilibrio. Un número considerable de estudios que han evaluado la hipótesis Janzen-Connell la han rechazado (Clark y Clark, 1984; Schupp, 1988b; Terborgh et al., 1993). Muchas de 
las especies arbóreas en la Isla de Barro Colorado, Panamá, parecen reclutar juveniles independientemente de la densidad de coespecíficos y de la distancia a los árboles coespecífcos (Hubbell y Foster, 1990b; Condit et al., 1992). Existe evidencia circunstancial de que las especies mas abundantes tienen mayor posibilidad de quedar representadas en la regeneración avanzada que las menos abundantes (Martínez-Ramos y Soto-Castro, 1993). No obstante, esta observación no discierne entre la posibilidad de que existan factores de mortalidad biótica que operan principalmente sobre especies de baja abundancia (cf. fig. 5b) y la posibilidad de que las especies de baja abundancia desaparezcan de la comunidad al ocurrir algún evento aleatorio de mortalidad (por ejemplo, la caída de una rama).

Como podría esperarse, la estructura comunitaria de la regeneración de avanzada puede depender de más de un solo mecanismo y la importancia de uno $u$ otro puede variar de un parche a otro y de un tiempo a otro dentro de un mismo parche. Por ejemplo, se ha observado que la diversidad de especies varía notablemente entre diferentes parches. En Los Tuxtlas, en dos de parches maduros, cuyo dosel alto estuvo dominado por el árbol Nectandra ambigens (Lauraceae), la comunidad de plántulas fue muy abundante y de muy baja diversidad ya que entre el 40 y $80 \%$ de las plántulas fueron de $N$. ambigens (Martínez-Ramos, 1991). En otros dos sitios, donde el árbol del dosel Pseudolmedia oxyphyllaria (Moraceae) fue dominante, la comunidad de plántulas presentó valores intermedios de abundancia y altos valores diversidad de especies. P. oxyphyllaria fue relativamente abundante pero otras especies presentaron abundancias equivalentes. Finalmente, un parche dominado por árboles maduros de Cecropia obtusifolia, presentó bajos valores de abundancia pero elevado de diversidad de especies (Martínez-Ramos, 1991). Tal variación en la comunidad de plántulas sugiere que el papel relativo de los mecanismos que reducen o aumentan la diversidad de especies puede cambiar de un parche a otro.

Un experimento de exclusión de vertebrados terrestres apoyó esta idea (Martínez-Ramos, 1991). Estos animales disminuyen notablemente la abundancia de semillas y plántulas de $P$. oxyphyllaria bajo la copa de los árboles progenitores (fig. 6a). Por lo tanto, los parches en los que este árbol domina los vertebrados juegan un papel importante en el mantenimiento de la diversidad de plántulas. Sin embargo, en los parches donde los árboles maduros de $N$. ambigens son dominantes, estos animales parecen desempeñar un papel contrario. En efecto, bajo la situación de exclusión, la diversidad aumentó respecto a la situación natural (efecto esperado en la fig. 6a). Bajo las copas de árboles maduros de $N$. ambigens los vertebrados tienden a comerse las semillas o las plántulas de otras especies y no aquellas de $N$ ambigens (Martínez-Ramos, 1991). No se sabe, sin embargo, si esto se debe a que las semillas y/o plántulas de $N$. ambigens son física o químicamente inaceptables como fuente de alimento de los vertebrados comedores de semillas y/o plántulas. El papel jugado por 
otros agentes bióticos puede compensar esta situación. Las plántulas de este árbol exhiben daños foliares notorios (necrosis, amarillamientos) causados por microorganismos (García-Guzmán, 1989) y daños del tallo causados por insectos (M. Martínez-Ramos, obs. pers.). Al parecer estos agentes son responsables de que a pesar de existir una enorme cantidad de plántulas muy pocas logren sobrevivir al estadio juvenil bajo la copa de los árboles adultos. En efecto, de 1,054 plántulas marcadas en 1988 (equivalente a una densidad promedio de $12.9 \mathrm{~m}^{2}$ ) menos del $5 \%$ quedaron vivas tres años después (M. Martínez-Ramos, datos no publicados). Por lo tanto, bajo la copa de los progenitores no se encuentran árboles jóvenes $N$. ambigens.

Finalmente, en los sitios en construcción, donde el dosel se encuentra principalmente ocupado por las copas de árboles pioneros, la emergencia local de plántulas es baja dado que las plántulas producidos por estos árboles no pueden establecerse bajo su propia sombra; en estos sitios la comunidad de plántulas depende de las semillas acarreadas al sitio por diferentes dispersores (Martínez-Ramos y Soto-Castro, 1993). El nulo efecto de la exclusión pudo deberse a que la baja cantidad de semillas que cae en estos parches no son atractivos a los vertebrados comedores de semillas; estos animales parecen tener su actividad alimenticia principalmente en sitios donde la cosecha de semillas es abundante (Martínez-Ramos, 1991).

No obstante las diferencias observadas de parche a parche, parece ser que en Los Tuxtlas las probabilidades de que ocurran reemplazos de árboles heteroespecíficos tiende a dominar sobre aquella de árboles coespecíficos. La generalidad de esta tendencia aguarda la realización de otros estudios similares en diferentes selvas.

Finalmente, es importante señalar que la expectativas de reemplazo entre especies, basada únicamente en la abundancia relativa de las mismas en la regeneración de avanzada, descansa en la suposición de que todas las especies responden de igual manera a los cambios ambientales que ocurren tras la caída de un árbol. Esta suposición podría representar la situación de igualdad competitiva entre especies señalada por Hubbell y Foster (1986b) en su hipótesis de deriva comunitaria. Sin embargo, esto podría no ser así. Si las especies responden de manera distinta a los claros, no necesariamente la especie más común en la regeneración de avanzada es la que con mayor probabilidad ocupará el hueco dejado por un árbol que cae. Un solo individuo (plántula o árbol joven) de una especie que crece rápidamente bajo la condición de un claro puede superar (y suprimir) a muchos de crecimiento lento. De esta manera, una especie con la estrategia más exitosa en el proceso de reemplazo entre árboles sería aquella que fuese capaz de; i) dispersar ampliamente sus propágulos (alta capacidad de colonizar nuevos parches), ii) de superar los riesgos de mortalidad preadulta y las limitaciones de crecimiento bajo las condiciones que imperan en los parches maduros y iii) que fuese capaz de crecer velozmente bajo las condiciones ambientales de los claros. ¿Es posible la existencia de tal especie ideal? 

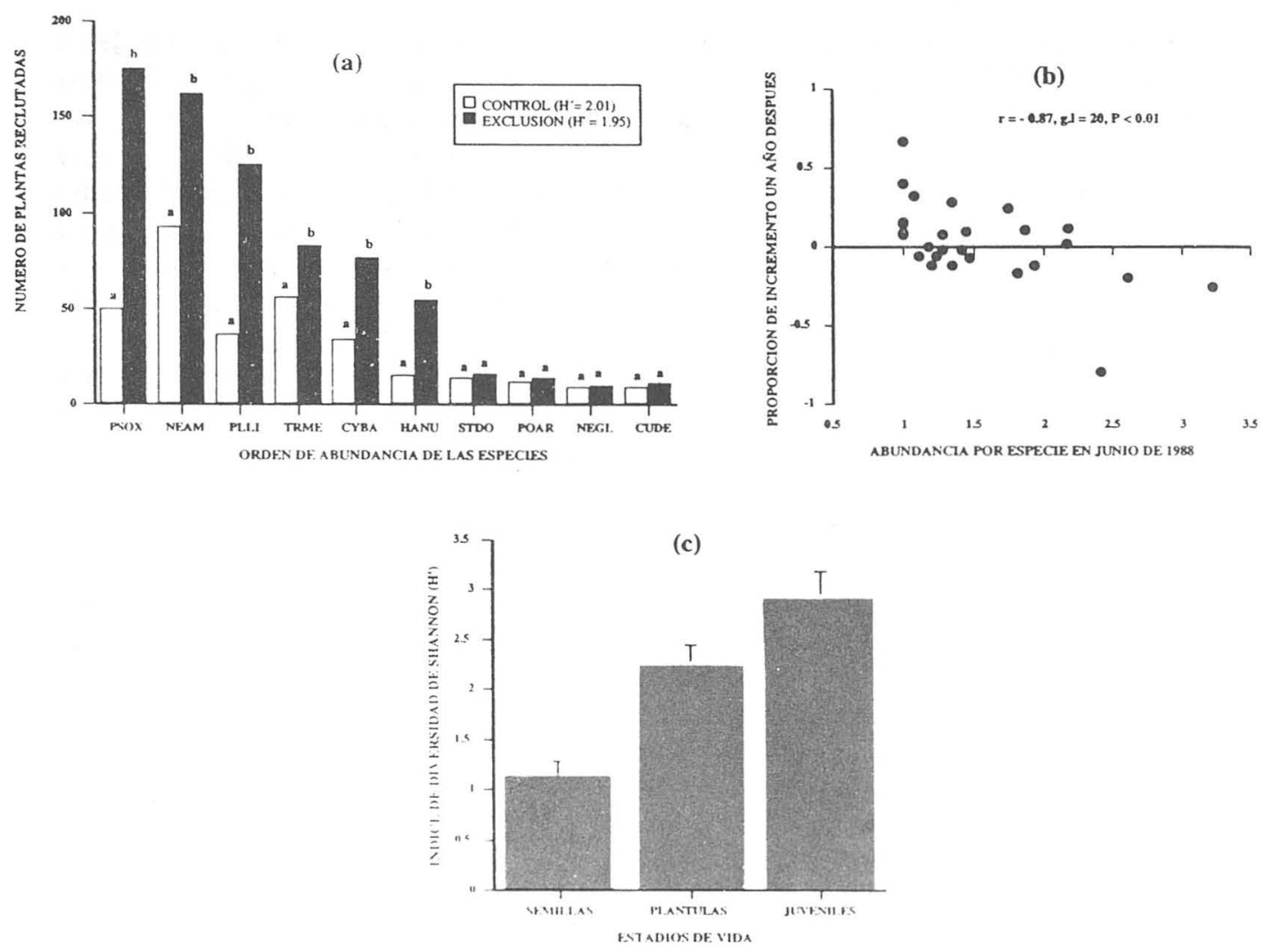

Fig 6. Evidencia de factores de regulación dependiente de la frecuencia en la comunidad de plántulas en Los Tuxtlas, Veracruz. a) Cambio en la tasa anual de natalidad de plántulas de las especies más comunes debido a la exclusión de vertebrados terrestres, para cada especic, letras diferentes indican diferencia significativas $(\mathrm{P}<0,05)$. PSOX $=$ Pseudolmedia oxyphyllaria (Moraceac). NEAM = Nectandra ambigens (Lauraceac), PLLI = Pleuranthodendron lindenii, TRI:MI: = Trophis mexicana, CYBA = ('ymbopetalum haillonii (Amnonaceac). HANU $=$ IIampea nutricea (Euphorbiaceae), STI) $)$ Stemmadenia donnell-Smithii $($ A pocynaceae), $\mathrm{P}() \wedge \mathrm{R}=$ Poulsenia armata (Moraceae), NEGL = Nectandra globosa (l auraceac), (IJ) $:=$ ('upania glabra (Sapindaceae). b) Efecto de la abundancia de las especies sobre su proporción de incremento en la comunidad de plántulas (note eje de las abscisas en escala log); cada punto representa una especies (modificado de Martinez-Ramos, 1991). c) ('ambio en la diversidad de especies entre comunidades de árboles que se encuentran en diferentes estadios de vida: semillas que ingresaron al suelo durante 1988 a 1989, plántulas ( 1 I de altura) censadas en junio de 1988 y árboles jóvenes ( $\geq 1 \mathrm{~m}$ de altura pero $\leq 1 \mathrm{~cm}$ de dap): las lineas verticales indican dos errores estándares (modilicado de Martine\%-Ramos y Soto-Castro, 1993). 
Esta pregunta puede responderse bajo la teoría de evolución de historias de vida, en particular de la teoría de asignación de recursos (Stearns, 1992). Esta teoría establece que la energía con que dispone un organismo la asigna a tres funciones principales que en última instancia determinan su posibilidad de dejar descendencia bajo un ambiente dado: mantenimiento, crecimiento y reproducción. Para sobrevivir, un organismo requiere de una energía mínima que permite satisfacer las necesidades respiratorias. Si la energía obtenida es mayor que la requerida para el mantenimiento se puede asignar el excedente a la función de crecimiento pero será a costa de aquella que pueda asignarse a la reproducción, y viceversa, si tal excedente no es grande. De esta manera la teoria establece que en un ambiente limitado en recursos la asignación más fuerte de energía es hacia el mantenimiento mientras que en ambientes ricos en recursos la asignación más importante es hacia el crecimiento y la reproducción. La evolución de atributos que permiten sobrevivir bajo condiciones limitantes pueden limitar la evolución de atributos que favorecen un crecimiento acelerado y una reproducción precoz y copiosa (ver Leigh. 1990 para más detalles). Estas relaciones negativas son conocidas como disyuntivas ("trade-offs") de atributos de historia de vida.

Existe evidencia de disyuntivas que impiden la evolución de la estrategia de reemplazamiento óptima. Por ejemplo, las especies que crecen como árboles juveniles de manera acelerada en los claros tienen baja sobrevivencia en la sombra (fig. 7b). Las especies que producen gran cantidad de semillas pequeñas que se diseminan ampliamente (y colonizan muchos parches) dan lugar a plántulas que no sobreviven en la sombra (fig. 4 b y fig. 7a) pero que crecen rápido en los claros. Por el contrario, las especies que no se dispersan (pues las semillas son muy grandes) tienen altas probabilidades de sobrevivir en la sombra (fig. 4 y 7a) como plántulas y árboles jóvenes pero no crecen tan rápidamente al abrirse el dosel (Brokaw, 1985b).

Estas disyuntivas pueden jugar también un papel muy importante en el mantenimiento de la diversidad a través del reemplazamiento de árboles que pertenecen a especies con atributos de historia de vida distintos. Por ejemplo, las especies que podrian dominar en abundancia la regeneración de avanzada (debido a atributos que confieren alta sobrevivencia en la sombra) tendrían pobre habilidad de colonización de nuevos parches debido a su baja capacidad de dispersión de semillas. Aún una especie de crecimiento rápido bajo los claros, que renueva plántulas de manera activa en la regeneración de avanzada podría alcanzar el dosel antes que la especie dominante. En el otro extremo, una especie con atributos que le impiden sobrevivir bajo la sombra podría colonizar el dosel antes que la dominante debido a la producción de una recurrente lluvia de semillas.

En resumen, la existencia de estas disyuntivas más la operación de interacciones bióticas que regulan la diversidad de especies en la regeneración de avanzada hacen sugerir que los fenómenos ecológicos (y biológicos en general) son 


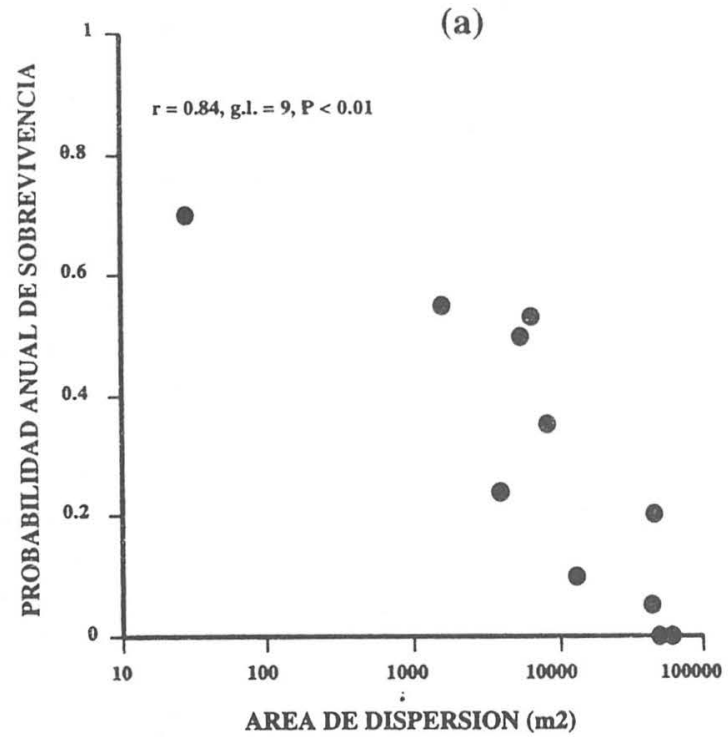

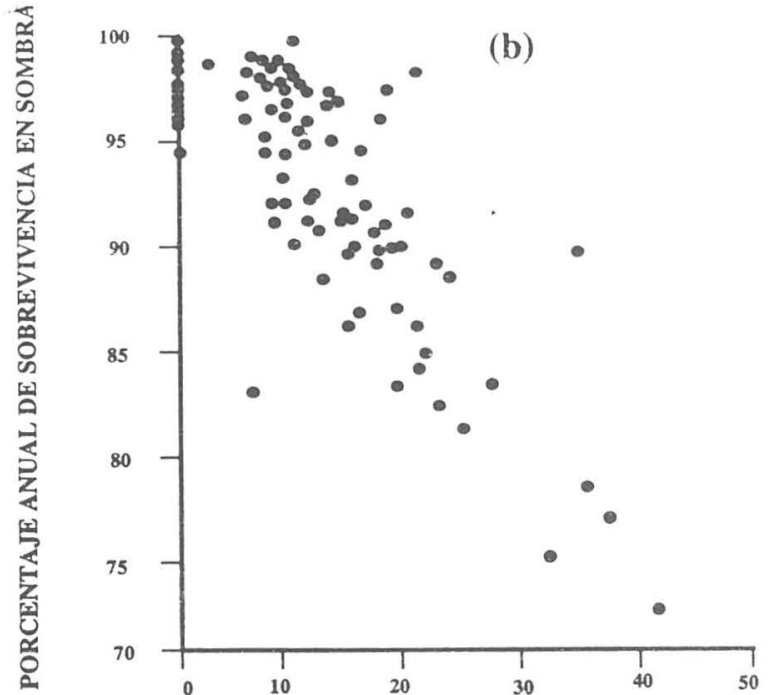

PORCENTAJE DE CRECIMIENTO ANUAL EN CLAROS

Fig. 7. Disyuntivas entre atributos de historia de vida de los árboles a nivel de la comunidad. a) Relación negativa entre la sobrevivencia de las plántulas bajo la sombra y la amplitud de dispersión en Los Tuxtlas, Veracruz (modificado de González-Méndez, 1994). b) Relación negativa entre el crecimiento en claros y la sobrevivencia en la sombra encontrada en la comunidad de árboles juveniles (dap: $1-4 \mathrm{~cm}$ ) en la Isla de Barro Colorado, Panamá (modificado de Hubbell y Foster, 1991). 
de mayor relevancia que los aleatorios en facilitar la coexistencia de especies a través de un proceso dinámico de reemplazamiento de árboles heteroespecíficos.

\section{CONCLUSIONES}

Muchas selvas húmedas poseen una enorme diversidad de especies arbóreas a escalas locales (de una o pocas hectáreas). El origen de tal riqueza de especies se relaciona con eventos de especiación alopátrica y migración de especies que han ocurrido a través de grandes escalas de tiempo y espacio. Al parecer, la especiación sirnpátrica, a través de la coevolución y diferenciación ecológica entre parejas de especies, ha jugado un papel relativamente menor en tal origen. Dado que la comunidad de árboles maduros representa el resultado de procesos de reclutamiento y muerte que se dan a medida que los árboles se desarrollan desde el estadio de semilla, el entendimiento de cómo se mantiene la diversidad de especies en el dosel descansa en entender cómo se organiza la comunidad de plántulas y árboles jóvenes antes y después de la apertura de claros en el dosel. En tal organización operan mecanismos ecológicos y aleatorios que tienden a elevar o disminuir la diversidad de especies en la regeneración de avanzada; la importancia de los diferentes mecanismos varían en su importancia relativa entre diferentes parches de selva. La diversidad de especies en la regeneración de avanzada también se encuentra mediada por notables atributos de los árboles (fisiológicos, morfológicos, de historia de vida). A mi parecer, los fenómenos ecológicos, más que los aleatorios, mantenienen la coexistencia de especies arbóreas a una escala local a través de un proceso activo de regeneración natural. Las interacciones bióticas (frugivoria, depredación), que favorecen la diversidad de especies en la regeneración de avanzada, y la existencia de disyuntivas en los atributos de historia de vida de los árboles, facilitan el mantenimiento de la gran diversidad de especies observadas en la comunidad de árboles maduros de muchas selvas húmedas.

AgRAdEcImientos. Este trabajo resuita del esfuerzo de muchas personas que han trabajado asociadas a los proyectos que llevo a cabo en Los Tuxtlas, Veracruz. En especial quisiera agradecer a Santiago Sinaca por su enorme ayuda en la identificación de material de campo y a todo el grupo de estudiantes del laboratorio de ecología de poblaciones y comunidades tropicales que tan amablemente han colaborado con las labores de campo y emprendido discusiones estimulantes. Agradezco al Dr. Ken Oyama su invitación a escribir esta revisión y su cuidadosa labor editorial. Este trabajo fue posible debido a los apoyos recibidos del Consejo Nacional de Ciencia y Tecnología, del Centro de Ecología, UNAM, y de la Estación de Biología Los Tuxtlas, IB (UNAM). Dedico este trabajo a la memoria de mi querido estudiante Jorge Vilchis. 


\section{LITERATURA CITADA}

AIDE, T.M. 1987. Limbfalls: a major cause of sapling mortality for tropical forest plants. Biotropica 19:284-285.

Álvarez-Buyl.ta, E. 1994. Density dependence and patch dynamics in tropical rain forests: matrix models and applications to a tree species. Am. Nat. 143:155-191.

Álvarez-Buylla, E. y M. Martint:7-Ramos. 1990. Seed bank versus seed rain in the regeneration of a tropical pioneer tree. Oecologia 84:314-325.

Álvarez-Buylla, E. y M. Martinez-Ramos. 1992. The demography of a neotropical pioneer tree: an evaluation of the pioneerclimax paradigm. J. Ecol. 8():275-29)().

Ashton, P.S. 1969. Speciation among tropical trees: some deductions in the light of recent evidence. Biol. J. Lin. Soc. 1:155-196.

Ashton, P.S. 1978. Crown characteristics of tropical trees. En: Tomlinson. P.B. y M.H. Zimmermann (Edrs.). Tropical trees as living systems. Cambridge University Press. Cambridge. pp. 591-615.

Asthon, P.S. y P. HALl. 1992. Comparisons of structure among mixed dipeterocarp forests of northwestern Borneo. J. Ecol. 80:459-481.

Augspurger, C.K. 1984a. Seedling survival of tropical tree species: interactions of dispersal distance. light gaps. and pathogens. Ecology 65: 17()5-1712.

Augspurger, C.K. 1984b. Light requirements of neotropical tree seedlings: a comparative study of growth and survival. J. Ecol. 72: 777-795

Augspurger, C.K. 1986. Morphology and dispersal potential of wind-dispersed diaspores of neotropical trees. Amer. J. Bot. 73: 353-363.

Augspurger, C.K. y C.K. Kelly. 1984. Pathogen mortality of tropical tree seedlings: experimental studies of the effects of distance, scedling density. and light conditions. Oecologia 61:211-217.

Augspurgitr, C.K y S.E. Franson. 1988. Input of wind-dispersed seeds into light gaps and forest sites in a neotropical forest. J. Trop. Ecol. 4:239-252.

Barton, A.M., N. Fetcher y S. Reidhead. 1989. The relationship between treefall gap size and light flux in a neotropical rain forest in Costa Rica. J. Trop. Ecol. 5:437-439.

BAZZAZ, F.A. 1984. Dynamics of wettropical forests and their species strategies. En: Medina. E.. H.A. Mooney y C. Vázquez-Yanes (Edrs.). Physiological ecology of plants in the wet tropics. Dr. Junk Publishers, Dordrecht, Netherlands. pp. 22.3-243.

BAZ7.AZ, F.A. 1991. Regeneration of tropical forests: physiological responses of pioneer and secondary species. En: Gómez-Pompa. A., T.C. Whitmore y M. Hadley (Edrs.). Rain forest regeneration and management. Man and the Biosphere Series. Volume 7. UNESCO, París. pp. 91-118.

BAZZAZ, F.A. y S.T.A. PICKLIT. 1980. The physiological ecology of tropical succession: a comparative review. Ann. Rev. Ecol. Syst. 11:287-310.

BAZZAZ, F.A. y D. AckERI,Y. 1992. Reproductive allocation and reproductive effort in plants En: Fenner, M. (Edr.). Secds: the ecology of regeneration in plant communitics C.A.B. International. Wallingford. U.K. pp. 126. 
Bazzaz, F.A., N.R. Chiarello, P.D. Coley y L.F. Pitelka. 1987. Allocating resources to reproduction and defense: new assessments of the costs and benefits of allocation patterns in plants and relating ecological roles to resource use. BioScience 37:58-67.

BECkER, P. y A. CASTILlo. 1990. Root architecture of shrubs and saplings in the understory of a tropical moist forest in lowland Panama. Biotropica 22:242-249.

Bongers, F., J. Popma, J. Meave y J. Carabias. 1988. Structure and floristic composition of the lowland rain forest of Los Tuxtlas, Mexico. Vegetatio 74:55-88.

BrokAW. N.V.L. 1982. Treefalls: frequency, timing, and consequences. En: Leigh, Jr., A.S., A.S. Rand y D. M. Windsor (Edrs.). The ecology of a tropical forest: seasonal rythms and longterm changes. Smithsonian Inst. Press., Washington, D.C. pp. 101-108.

BROKAW, N.V.L. 1985a. Treefalls, regrowth, and community structure in tropical forests. En: Pickett. T.A.y P.S. White (Edrs.). The ecology of natural disturbance and patch dynamics. Academic Press, New York. pp. 53-69.

BROKAW, N.V.L. 1985b. Gap phase regeneration in a tropical forest. Ecology 66:682-687.

BROKAW, N.V.L. 1987. Gap phase regeneration of three pioneer tree species in a tropical forest. J. Ecol. 75:9-19.

Brokaw, N.V.L. y S.M. Scheiner. 1989. Species composition in gaps and structure of a tropical forest. Ecology 70:538-541.

CARABIAS, J. y S. Guevara. 1985. Fenología de una selva tropical húmeda y en una comunidad derivada, Los Tuxtlas. Veracruz. En: Gómez-Pompa, A. y S. Del Amo (Edrs.). Investigaciones sobre la regeneración de selvas altas en Veracruz, México Vol II. Alhambra, México.pp. 27-66

CAREAGA, S. 1989. Efecto de la variación en el tamaño de la semilla sobre el desarrollo de plántulas de especies tropicales. Tesis Profesional, Universidad Nacional Autónoma de México, México.

CHAZDON, R.L. 1985. Leaf display, canopy structure, and light interception of two understory palm species. Amer. J. Bot. 72:1493-1502.

Chazdon, R.L. 1988a. Sunfleck and their importance to forest understory plants. Adv. Ecol. Res. 18:1-63.

CHAZDON, R.L. 1988b. The costs of leaf support in understory palms: economy versus safety. Am. Nat. 127:9-30.

Chazdon, R. L. y N. Fetcher. 1984. Photosynthetic light environments in a lowland tropical rain forest in Costa Rica. J. Ecol. 72:553-564.

Chazdon, R.L., K. Williams y C.B. Field. 1988. Interactions between crown structure and light environments in five rainforest Piper species. Amer. J. Bot. 75:1459-1471.

Chesson, P.L. y T.J. CASE. 1986. Overview: nonequilibrium commnuity theories: chance, variability, history, and coexistence. En: Diamond, J. y J. Case (Edrs.). Community ecology. Harper and Row, New York. pp. 229-239.

Chiarello, N. 1984. Leaf energy balance in the wet lowland tropics. En: Medina, E., H.A. Mooney y C. Vázquez-Yanes (Edrs.). Physiological ecology of plants in the wet tropics. Dr. Junk Publishers, Dordrecht, Netherlands. pp. 85-98.

CLARK, D.B. 1990. The role of disturbance in the regeneration of neotropical moist forests. En: Bawa, K.S. y M. Hadley (Edrs.). Reproductive ecology of tropical forest plants. Man and the Biosphere Series, Volume 7. UNESCO, París. pp. 291-315. 
CLARK, D.A. y D.B. ClARK. 1984. Spacing dynamics of a tropical rain forest tree: evaluation on the Janzen-Connell model. Am. Nat. 142:769-788.

CLARK, D.A. y D.B. CLARK. 1985. Seedling dynamics of a tropical tree: impacts of herbivory and meristem damage. Ecology 66:1884-1892.

ClARK, D.A. y D.B. ClARK. 1987. Análisis de la regeneración de árboles del dosel en bosque muy húmedo tropical. Aspectos teóricos y prácticos. Rev. Biol. Trop. 35 (supl. 1): 41-54.

CLARK, D.B. y D.A. CLARK. 1989. The role of physical damage in the seedling mortality of a neotropical rain forest. Oikos 55: 225-230.

CLARK, D.B.y D.A. CLARK. 1991. The impact of physical damage on canopy tree regeneration in a tropical rain forest. J. Ecol. 79:447-458.

COLEY, P.D. 1983. Herbivory and defensive characteristics of tree species in a lowland tropical forest. Ecol. Monog. 53:209-233.

COLEY, P.D., J.P. BRYANT y F.S.CHAPIN III. 1985. Resource availability and plant antiherbivore defense. Science 230:895-899.

Condit, R., S.H. HubBELl y R.B. FosteR. 1992. Recruitment near conspecific adults and the maintenance of tree and shrub diversity in a neotropical forest. Am. Nat. 140: 261-286.

Condit, R., S.H. HubBELl y R.B. Foster. 1994. Density dependence in two understory tree species in a neotropical forest. Ecology (en prensa).

CONNEL, J.H. 1971. On the role of natural enemies in preventing competitive exclusion in some marine and in rain forest trees. En: Den Boer, P.J. y G.R. Gradwell (Edrs.). Dynamics of populations. Centre for Agriculture Publising and Documentation, Wageningen. pp. 298-310.

CONNELl, J. H. 1989. Some processes affecting the species composition in forest gaps. Ecology 70:560-562.

Connell, J.H., J.G. TraceY y J.J. WeBB. 1984. Compensatory recruitment, growth, and mortality as factors maintaining rain forest tree diversity. Ecol. Monog. 54: 141-164.

Córdova, B. 1985. Demografia de árboles tropicales. En: Gómez-Pompa, A. y S. Del Amo (Edrs.). Investigaciones sobre la regeneración de selvas altas en Veracruz, México Vol II. Alhambra, México. pp. 103-128.

CoRnEll, H.V. y J.H. LAWTON. 1992. Species interactions, local and regional processes, and limits to the species richness of ecological communities: a theoretical perspective. J. Anim. Ecol. 58:1003-1020.

CRONQuist, A. 1981. An integrated system of classification of flowering plants. Columbia University Press, New York.

DE LA CRUZ, M. y R. DiRzo. 1988. A survey of the standing levels of herbivory in seedlings from a Mexican rain forest. Biotropica 19:98-106.

DENSLOw, J. 1987. Tropical rain forest gaps and tree species diversity. Ann. Rev. Ecol. Syst. 18: $432-451$.

DENSLOw, J.S. y A.E. GómEZ-DíAZ. 1990. Seed rain to treefall gaps in a neotropical rain forest. Can. J. For. Res. 20:642-648. 
Denslow, J.S., J.C. Schulz, P.M. Vitousek y B.R. StranN. 1990. Growth responses of tropical shrubs to treefall gap environments. Ecology 71:165-179.

DeStevens, D. 1989. Genet and ramet demography of Oenocarpus mapora ssp. mapora, a clonal palm of a Panamanian tropical moist forest. J. Ecol. 77: 579-596.

DiRzo, R. 1984. Herbivory: a phytocentric overview. En: Dirzo, R. y J. Sarukhán (Edrs.). Perspectives on plant population ecology. Sinauer Ass. Inc., Sunderland, MA. pp. 141-165.

Dirzo, R. 1987. Estudios sobre interacciones planta-herbívoro en "Los Tuxtlas", Veracruz. Rev. Biol. Trop. (supl. 1) 35:119-132.

Dirzo, R. y C. Domínguez. 1986. Seed shadows, seed predation and the advantages of seed dispersal. En: Estrada, A. y T.H. Fleming (Edrs.). Frugivores and seed dispersal. Dr. Junk Publishers, Dordrecht, Netherlands. pp. 237-249.

DiRZO, R. y A. MIRANDA. 1991. Altered patterns of herbivory and diversity in the forest understory: a case of the possible causes of contemporary defaunation. En: Price, P.W., T.M. Lewinsohn, G.W. Fernández, W.W. Benson (Edrs.). Plant-animal interactions: evolutionary ecology in tropical and temperate forests. Wiley, New York. pp. 273-297.

Dirzo, R., C. Horvitz, H. Quevedo y M.A. López. 1992. The effects of gap size and age on the understory herb community of a tropical Mexican rain forest. J. Ecol. 80:809-822.

DOBZHANSKY, T. 1950. Evolution in the tropics. Am. Sci. 38:209-221.

EstradA, A. 1984. Fruit eating, dispersal by howler monkeys (Allouatta palliata) in the tropical rain forests of Los Tuxtlas, Veracruz, Mexico. J. Primatol. 6:77-91.

Estrada, A. y T.H. Fleming (Edrs.). 1986. Frugivores and seed dispersal. Dr. Junk Publishers, Dordrecht, Netherlands.

Estrada, A., R. Coates-Estrada y C. VÁzQuez-Yanes. 1984. Observations of fruiting and dispersers of Cecropia obtusifolia at Los Tuxtlas, Mexico. Biotropica 16:315-318.

FEDERov, A.A. 1966. The structure of the tropical rain forest and especiation in the humid tropics. J. Ecol. 54:1-11.

FEnNer, M. 1985. Seed ecology. Chapman and Hall, London.

Fetcher, N., S.F. Oberbauer y B.R. Stain. 1985. Vegetation effects on macroclimate in lowland tropical forest in Costa Rica. Int. J. Biometer. 29:145-155.

Fleming, T.H. y A. EstradA. (Edrs.) 1993. Frugivory and seed dispersal: ecological and evolutionary aspects. Kluwer Academic Publishers, Dordrech, Holanda.

Foster, R.B. 1990. Ciclo estacional de caída de frutos en la isla de Barro Colorado. En: Leigh Jr. E.G., R.A. Stanley y D.M. Windsor (Edrs.). Ecología de un bosque tropical: ciclos estacionales y cambios a largo plazo. Smithsonian Tropical Research Institute, Panamá. pp. 219-241.

FosTER, S.A. 1986. On the adaptive value of large seeds for tropical moist forest trees: a review and synthesis. Bot. Rev. 52:269-299.

FOSTER, S.A. y C.H. JANSON. 1985. The relationship between seed size and establishment conditions in tropical woody plants. Ecology 66:773-780.

Frankie, G.W., H.G. BAKER y P.A. Opler. 1974. Comparative phenological studies of trees in tropical wet and dry forests in the lowlands of Costa Rica. J. Ecol. 62:881-919. 
GARcíA-GuZMÁn, G. 1990. Estudio sobre la ecología de patógenos en el follaje de plantas de la selva de Los Tuxtlas. Tesis de Maestría. Universidad Nacional Autónoma de México, México.

GARWOOD, N. C., D. JANOS Y N. BROKAW. 1979. Earthquake-caused landslides: a major disturbance to tropical forest. Science 205: 997-999.

GARWOOD, N.C. 1983. Seed germination in a seasonal tropical forest in Panama: a community study. Ecol. Monog. 53:159-184.

Garwood, N.C. 1989. Tropical soil seed banks: a review. En: Leck, L.A., R.L. Simson y V.T. Parker (Edrs.). Ecology of seed banks. Academic Press, USA. pp. 149-190.

GAUSS, G.F. 1934. The struggle for existence. Williams and Wilkins, Baltimore.

GENTRY, A.H. 1982. Neotropical floristic diversity: phytogeographical connections between Central and South America, pleistocene climatic fluctuations, or an accident of the Andean orogeny? Ann. Missouri Bot. Gard. 69:557-593.

GENTRY, A.H. 1988. Tree species richness of upper Amazonian forests. Proc. Nat. Acad. Sci. USA $85: 156-159$.

GENTRY, A. 1990. Four neotropical rainforests. Yale University Press, New Haven.

GENTRY, A.H. y ORTIZ, R.S. 1993. Patrones de composición florística en la amazonia peruana. En: Kalliola, R., M. Puhakka y W. Danjoy (Edrs.). Amazonia Peruana: vegetación húmeda tropical en el llano subandino. Gummenus Printing, Jyväskylä, Finlandia. pp. 155-166.

Gilbert, G.S., S.P. HubBell y R.B. Foster. 1994. Density and distancetoadult effects of a canker disease of trees in a moist tropical forest. Oecologia 98:100-108.

Gómez-PomPa, A. y S. DEL Amo (Edrs.). 1985. Investigaciones sobre la regeneración de selvas altas en Veracruz, México, Vol. II. Alhambra, México.

GonZÁleZ-MÉnDEZ, M. 1994. Variación interespecífica en las tasas de dispersión de semillas en una selva húmeda de México. Tesis Profesional, Facultad de Ciencias, UNAM.

Gorchov, D.L., F. CoRneJo, C. Ascorra y M. JARAMILlO. 1993. The role of seed dispersal in the natural regeneration of a rain forest after strip-cutting in the Peruvian Amazon. Vegetatio 108:339-349

Guevara, S. y J. LABORDE. 1993. Monitoring seed dispersal at isolated standing trees in tropical pastures: consequences for local species availability. Vegetatio 108:319-338.

Hallè, F., R.A. OLDEMAN y P.B. TOMLINSON. 1978. Tropical trees and forests: an architectural analysis. Springer-Verlag, New York.

HART, T.B., J.A. HART, y P.MurPhY. 1989. Monodominant and species-rich forest of the humid tropics: causes for their co-ocurrence. Am. Nat. 133: 613-633.

Hartshorn, G. 1978. Tree falls and tropical forest dynamics. En: Tomlinson, P.B. y M.H. Zimmerman (Edrs.). Tropical trees as living systems. Cambridge, London. pp. 617-638.

HLadik, A. y S. MiQuel. 1990. Seedling types and plant establishment in an African rain forest. En: Bawa, K.S. y M. Hadley (Edrs.). Reproductive ecology of tropical forest plants. Man and the Biosphere Series, Volume 7. UNESCO, París . pp. 261-282.

Holthuljzen, A.M.A. y J.H.A. Boerboom. 1982. The Cecropia seed bank in the Surinam lowland rain forest. Biotropica 14:62-68. 
Hopkins, M. y A.W. Graham. 1987. The viability of seeds of rainforest species after experimental burials under tropical lowland forest in northeastern Australia. Aust. J. Ecol. 12:97-108.

HowE. H.F. 1990a. Seed dispersal by birds and mammals: implications for seedling demography. En: Bawa, K.S. y M. Hadley (Edrs.). Reproductive ecology of tropical forest plants. Man and the Biosphere Series, Volume 7. UNESCO, París. pp. 261-282.

HowE. H.F. 1990b. Survival and growth of juvenile Virola surinamensis in Panama: effects of herbivory and canopy closure. J. Trop. Ecol. 6: 259-280.

HowE. H.F. y G.F. EsTABROOK. 1977. On intraspecific competition for avian dispersers in tropical trees. Am. Nat.111: 817-832.

HOWE. H.F. y W.M. RITCHER. 1982. Effects of seed size on seedling size in Virola surinamensis a within and between tree analysis. Oecologia 53:347-351.

HubBEL.L, S.P. 1979. Tree dispersion. abundance and diversity in a tropical rain forest. Science 199:1302-1310.

Hubbell. S. P. y R.B. Foster. 1983. Diversity of canopy trees in a neotropical forest and implications for conservation. En: Sutton, S. T.C. Whitmore y A. Chadwick (Edrs.). Tropical rainforest: ecology and management. Blackwell, Oxford. pp. 25-41.

Hi ibBELl. S.P. y R.B. Foster. 1986a. Canopy gaps and the dy namics of a tropical forest. En: Crawley, M. (Edr.). Plant ecology. Blackwell Scientific Publications, Oxford. pp. $77-96$

Hu BBELL. S. P. y R.B. FosTER. 1986b. Biology, chance, and history and the structure of tropical rainforest tree communities. En: Diamond. J. y J.T. Case (Edrs.). Community ecology. Harper and Row. New York. pp. 314-329.

Hu BBEI.L. S. P. y R.B. FosTER. 1986c. Commonness and rarity in a neotropical forest: implications for tropical tree conservation. En: Soulé. M. (Edr.). Conservation biology: science of scarcity and diversity. Sinauer Associates, Massachusetts. pp. 205-231.

Hı BBili. S.P. y R.B. Foster. 1987. La estructura espacial en gran escala de un bosque tropical. Rev. Biol. Trop. (supl. 1) 35: 7-22

HI 'BBBILI. S.P. y R.B. F(OSTER. 199()a. Structure. dy namics, and equilibrium status of oldgrowth foresi on Barro Colorado Island. En: Gentry, A.H. (Edr.). Four neotropical forests. Yale University Press. New Haven. pp. 522-541.

H(IBIBF.I. S.P. y R. B. F(ISTI:R. 1990)b. The fate of juvenile trees in a neotropical forest: implications for the natural maintenance of tropical tree diversity. En: Bawa, K.S. y M. Hadley (Edrs.). Reproductive ecology of tropical forest plants. Man and the Biosphere Scrics. Volume 7. UNESCO. París. pp. 317-344.

H(IBBII1, S.P. y R.B. F(OSTLR. I99)c. Presence and absence of density dependence in a neotropical tree community. Phil. Trans. R. Soc. London. B 330:269-281.

HU B31311.1. S.P. y R.B. FostiR. 1991. Short-term dynamics of a neotropical forest: why ccological research matters to tropical conservation and management. Oikos 63: $48-61$

IBARRA-MANRIQUT\%. G. 1985. Estudios preliminares sobre la flora leñosa de la estación de Biología Tropical, Los Tuxtlas. Veracnuz. México. Tesis Profesional, Facultad de Ciencias. Universidad Nacional Autónoma de México. 
IBARRA-MANRíquez, G. y S. SinACA. 1987. Listados florísticos de México VII. Estación de Biología Tropical Los Tuxtlas. Inst. Biol., UNAM.

IbARrA-ManríQueZ, G., B. SÁnchEZ-Garfias y L. GonZÁleZ-García. 1991. Fenología de lianas y árboles anemócoros en una selva cálido-húmeda de México. Biotropica 23:242-254.

IBARRA-MANRÍQUEZ, G. y K. OYAMA. 1992. Ecological correlates of reproductive traits of Mexican rain forest trees. Amer. J. Bot. 79:383-391.

JACKSON, J.F. 1981. Seed size as a correlate of temporal and spatial patterns of seed fall in a neotropical forest. Biotropica 3:121-130.

JANSON, C.H. 1983. Adaptations of morphology to dispersal agents in a neotropical forest. Science 219:187-189.

JANZEN, D.H. 1969. Seed-eaters versus seed size, number, toxicity, and dispersal. Evolution 23:1-27.

JANZEN, D.H. 1970. Herbivores and the number of tree species in tropical forest. Am. Nat. 104:501-528.

JANZEN, D.H. 1971. Seed predation by animals. Ann. Rev. Ecol. Syst. 2: 465-492.

JANZEN, D.H. 1978. Seeding patterns in tropical trees. En: Tomlinson, P.B. y M.H. Zimmerman (Edrs.). Tropical trees as living systems. Cambridge, London. pp. 83-128.

KING, D.A. 1990. Allometry of saplings and understorey trees of a panamenian forest. Functional Ecol. 4: 27-32.

KoHOYAmA, T. 1991. A functional model describing sapling growth under a tropical forest canopy. Functional Ecol. 5:83-90.

Langenheim, J.H., C.B. Osmond, A.Brooks y P.J. Ferrar. 1984. Photosynthetic responses to light in seedlings of selected Amazonian and Australian rainforest tree species. Oecologia 63:215-224.

LAWTON, R.O. 1990. Canopy gaps and light penetration into a windexposed tropical lower montane forest. Can. J. For. Res. 20:659-667.

LAWTON, R.O. y F.E. PUTZ. 1988. Natural disturbance and gapphase regeneration in a windexposed tropical cloud forest. Ecology 69:764-777.

LEIGHT, Jr., E.G. 1990. Introducción: ¿por qué hay tantos tipos de árboles tropicales? En: Leigh, Jr. E.G., A.S. Rand y D.M. Windsor (Edrs.). Ecología de un bosque tropical: ciclos estacionales y cambios de largo plazo. Smithsonian Inst. Press, Washington, D.C. pp. $75-112$.

Lieberman, M., R. Peralta y D. Lieberman. 1989. Forests are not just Swiss cheese: canopy estereogeometry of nongaps in tropical forests. Ecology 70:550-552.

Lieberman, D., M. Lieberman, R. Peralta, y G. Hartshorn. 1985a. Mortality patterns and stand turnover rates in a wet tropical forest in Costa Rica. J. Ecol. 73:915-109.

Lieberman, D., M. Lieberman, R. Peralta, y G. Hartshorn. 1985b. Growth rates and age-size relationships of tropical wet forest trees in Costa Rica. J. Trop. Ecol. 1:97-109.

MacArthur, R.H. y E.O. Wilson, 1967. The theory of island biogeography. Princeton University Press, New Jersey.

MagurRan, A.E. 1988. Ecological diversity and its measurement. Princeton University Press, Princeton, N.J. 
MARQUIS, R. J., H.J. YounG y H.E. BRAKER. 1986. The influence of understorey vegetation cover on germination and seedling establishment in a tropical lowland wet forest. Biotropica 18: 273-278.

MARTíneZ DEL Río, C. y C. RESTREPo. 1993. Ecological and behavioral consequences of digestion in frugivorous animals. Vegetatio 107:205-216.

MARTÍNEZ-RAMOS, M. 1985. Claros, ciclos vitales de los árboles tropicales y la regeneración natural de las selvas altas perennifolias. En: Gómez-Pompa, A. y S. Del Amo (Edrs.). Investigaciones sobre la regeneración de selvas altas en Veracruz, México Vol II. Alhambra, México. pp. 191-239.

MartíneZ-RAmOS, M. 1991. Patrones, procesos y mecanismos en la comunidad de plántulas de una selva húmeda neotropical. Tesis doctoral, Universidad Nacional Autónoma de México, México.

Martinez-Ramos, M. y A. Soto-Castro. 1993. Seed rain and advanced regeneration in a tropical rain forest. Vegetatio 108:299-318.

Martínez-Ramos, M. y E. Álvarez-Buylla. 1986. Gap dynamics, seed dispersal and tree recruitment: the case of Cecropia obtusifolia at Los Tuxtlas, México. En: Estrada, A. y T.H. Fleming (Edrs.). Frugivores and seed dispersal. Dr. Junk Publishers, Dordrecht, Netherlands. pp. 323-346.

Martínez-Ramos, M., Sarukhán, J. y Piñero, D. 1988a. The demography of trees in the context of forest gap dynamics: The case of Astrocaryum mexicanum at Los Tuxtlas tropical rain forest. En: Davy, D.J., M.J. Hutchings y A.R. Watkinson (Edrs.). Plant population ecology. Blackwell, Oxford, U.K. pp. 293-313.

Martínez-Ramos, M., E. Álvarez-Buylla, J. Sarukhán y D. Piñero. 1988b. Treefall age determination and gap dynamics in a tropical rain forest. J. Ecol. 76: 700-716.

Miranda, F. y E. HERnÁndEZ-X. 1963. Los tipos de vegetación de México y su clasificación. Bol. Soc. Bot. México 29: 20-179.

Molofsky, J. y C. K. Augspurger. 1992. The effect of leaf litter on early seedling establishment in a tropical forest. Ecology 73:68-77.

Newstrom, L.E., G.W. Frankie, H.G. Baker y R.K. Colwell. 1994. Diversity of longterm flowering patterns. En: McDade, L.A., K.S. Bawa, H.A. Hespenheide y G.S. Hartshorn (Edrs.). La Selva: ecology and natural history of a neotropical rain forest. The University of Chicago Press, Chicago. pp. 142-160.

NG, F.S.P. 1978. Strategies of establishment in Malayan forest trees. En: Tomlinson, P.B. y M.H. Zimmerman (Edrs.). Tropical trees as living systems. Cambridge, London. pp. 129-162.

NG, F.S.P. 1980. Germination ecology of Malayan woody plants. Malay. For. 43: 406-437.

OBERBAUER, F. 1990. Seed weight and rooting depth of seedlings of Costa Rican wet forest trees. Rev. Biol. Trop. 38 (supl. 2): 475-478.

Palomeque, R. 1988. Demografía y herbivoría de Omphalea oleifera en Veracruz. Unpublished dissertation. Universidad Nacional Autónoma de México, México.

PÉrEZ-NASER, N. y C. VÁZQUEZ-YANES. 1986. Longevity of buried seed from some tropical rain forest trees and shrubs of Veracruz, Mexico. Malay. For. 49: 352-356.

Piñero, D., M. Martínez-Ramos y J. SARUKHÁN. 1984. A population model of Astrocaryum mexicanum and a sensitivity analy sis of its finite rate of increase. J. Ecol. 72: 977-991.

POPMA, J. y F. BONGERS. 1988. The effect of canopy gaps on growth and morphology of rain forest trees. Oecologia 75: 625-632. 
Popma, J., F. Bongers, M. Martínez-Ramos y E. VeneklaAs. 1988. Pioneer species distribution in treefall gaps in neotropical rainforest: a gap definition and its consequences. J. Trop. Ecol. 4: 77-88.

Prance, G.T. 1982. Biological diversification in the tropics. Columbia Univ. Press, New York.

PrIMACK, R.B. 1993. Essentials of conservation biology. Sinauer Associates, Inc. Massachusetts.

PuTZ, F.E. y N.V.L. BroKaw. 1989. Sprouting of broken trees on Barro Colorado Island. Panama. Ecology 70: 508-512.

Putz, F.E., P.D. Coley, L. Lu, A. Montalvo, y A. Aiello. 1983. Uprooting and snapping of trees: structural determinants and ecological consequences. Can. J. For. Res. 13:1001-1020.

RAich, J. W. y N.L. Christensen. 1989. Malaysian Dipterocarp forest: tree seedling and sapling species composition and small scale disturbance patterns. Nat. Geogr. Res. 5: 348-363.

RAVEN, P.H. y D.I. AxELRoD. 1974. Angiosperm biogeography and past continental movements. Ann. Missouri. Bot. Gard. 61: 539-673.

Richards, P.W. 1957. The tropical rain forest. 2a. edición. Cambridge University Press. Cambridge.

RickleFs, R.E. y D. Schluter (Edrs.). 1993. Species diversity in ecological communitics historical and geographical perspectives. The University of Chicago Press, Chicago.

RoDrígueZ, J. 1994. El efecto de la heterogeneidad ambiental y la densidad sobre la remoción de semillas en una palma tropical. Tesis Profesional. Facultad de Ciencias, UNAM.

Rzedowsky, J. 1978. Vegetación de México. Ed. Limusa, México.

SALO, J. 1993. Notas en la historia de la exploración científica y teorías en la selva baja de la amazonia peruana. En: Kalliola, R., M. Puhakka y W. Danjoy (Edrs.). Amazonia Peruana: vegetación húmeda tropical en el llano subandino. Gummerus Printing. Jyväskylä, Finlandia. pp. 9-22.

SAMPER, C. 1992. Natural disturbance and plant establishment in an Andean cloud forest. Tesis Doctoral. Harvard University, Cambridge, Massachusetts.

SARUKHÁn, J. 1968. Análisis sinecológico de la selva de Terminalia amazonica en la planicie costera del Golfo de México. Tesis de Maestría. Colegio de Postgraduados. ENA. Chapingo, México.

SARukhán, J. 1980. Demographic problems in a tropical system. En: Solbrig, O.T. (Edr.). Demography and evolution in plant populations. University of California Press. Berkeley. pp. 168-188.

Sarukhán K.J., D. Piñero y M. Martínez-Ramos. 1985. Plant demography: a community level interpretation. En: White, J. (Edr.). Studies in plant demography: a festschrift for John L. Harper. Academic Press, London. pp. 17-31.

Schupp, E.W. 1988a. Seed and early seedling predation in the forest understory and in treefall gaps. Oikos 51: 525-530.

Schupp, E.W. 1988b. Factors affecting post-dispersal seed survival in a tropical forest. Oecologia 76:525-530.

STEARns, S.C. 1992. The evolution of life histories. Oxford University Press. Oxford.

Strauss-DEBEnEDETTI, S. y F.A. BAZZAZ. 1991. Plasticity and acclimation to light in tropical Moraceae of different successional positions. Oecologia 87:377-387. 
SwaIne, M.D. y T.C. Whitmore. 1988. On the definition of ecological species groups in tropical forests. Vegetatio 75:81-86.

Terborgh, J., E. Losos, M.P. Ripley y M. Bolaños-Riley. 1993. Predation by vertebrates and invertebrates on the seeds of five canopy tree species of an Amazonian forest. Vegetatio 108: 375-386.

Toledo, V. 1982. Pleistocene changes of vegetation in tropical Mexico. En: Prance, G.T. (Edr.). Biological diversification in the tropics. Columbia University Press, New York. pp. 93-111.

Tomlinson, P.B. 1987. Architecture of tropical plants. Ann. Rev. Ecol. Syst. 18: 1-21.

Uhl, C.. Clark, K., N. Dezzeo y P. MaQuirino. 1988. Vegetation dynamics in amazonian treefall gaps. Ecology 69: 751-763

VAndermeER, J.H. 1977. Notes on density dependence in Welfia georgii Wend. ex Buret (Palmae) a lowland rainforest species in Costa Rica. Brenesia 1011:9-15

VÁZQuEZ-YANES, C. 1980. Notas sobre la autoecología de los árbolies pioneros de rápido crecimiento de la selva tropical lluviosa. Trop. Ecol. 21: 103-112.

VÁZQuez-YANES, C. y A. OROZCO-SEGOVIA. 1984. Ecophysiology of seed germination in tropical humid forest of the word: a review. En: Medina, E., H.A. Mooney y C. Vázquez-Yanes (Edrs.). Physiological ecology of plants in the wet tropics. Dr. Junk Publishers, Dordrecht, Netherlands. pp. 37-49.

VÁzQuez-Yanes, C. y A. Orozco-Segovia. 1993. Patterns of seed longevity and germination in the tropical rainforest. Ann. Rev. Ecol. Syst. 24:69-87.

Vázquez-Yanes, C., Orozco-Segovia, A., Rincón, E., SÁnchez-Coronado, M.E., Huante, P., BARRAdas, V. y Toledo, J.R. 1990. Light beneath the litter in a tropical forest: effect on seed germination. Ecology 71: 1952-1958.

VITOUSEK, P. y J.S. Denslow. 1986. Nitrogen and phosphorous availability in treefall gaps in a lowland tropical forest. J. Ecol. 74: 1167-1178.

WENDT. T. 1993. Composition, floristic affinities, and origins of the canopy tree flora of the Mexican Atlantic slope rain forests. En: Ramamoorthy, T.P., R. Bye y A. Lot (Edrs.). Biological diversity of Mexico: origins and distribution. Oxford University Press, New York. pp. 595-680

WheE.t.WRIGHT, N.T. 1985. Fruit size, gape with, and the diets of fruiteating birds. Ecology 66: 808-818.

WhEELWRIGHT, N.T. 1986. A seven year study of individual variation in fruit production in tropical birddispersed tree species in the family Lauraceae. En: Estrada, A. y T.H. Fleming (Edrs.). Frugivores and seed dispersal. Dr. Junk Publishers, Dordrecht, Netherlands. pp. 21-35.

WheEl, Wright, N.T. 1993. Fruit size in a tropical tree species: variation, preference by birds, and heretability. Vegetatio 107:163-175.

Whitmore, T. C. 1978. Gaps in the forest canopy. En: Tomlinson, P.B. y M.H. Zimmerman (Edrs.). Tropical trees as living systems. Cambridge, London. pp. 669-655.

Whitmore, T.C. 1982. On pattern and process in forests. En: Davy, D.J., M.J. Hutchings y A.R. Watkinson (Edrs.). Plant population ecology. Blackwell, Oxford, U.K. pp. $45-60$. 
Whitmore, T.C. 1984. Tropical rain forest of the far east. 2da. Edición. Clarendon, Oxford. WhITMORE, T.C. 1989. Canopy gaps and two major groups of forest trees. Ecology 70:536-538.

Williams, K., C.B. Field y H. A. Mooney. 1989. Relationships among leaf construction, leaf longevity, and light environments in rainforest plants of the genus Piper. Am. Nat. 133:188-211.

YAP, S.K. y H.T. Chan. 1990. Phenological behaviour of some Shorea species in Peninsular Malaysia. En: Bawa, K.S. y M. Hadley (Edrs.). Reproductive ecology of tropical forest plants. Man and the Biosphere Series, Volume 7. UNESCO, París. pp. 21-35. 